\title{
Alkali-activation potential of biomass-coal co-fired fly ash
}

\author{
Christopher R. Shearer ${ }^{*}, \mathrm{a}, 1$, John L. Provis ${ }^{\mathrm{b}}$, Susan A. Bernal ${ }^{\mathrm{c}}$, Kimberly E. Kurtis ${ }^{\mathrm{a}}$
}

${ }^{\mathrm{a}}$ School of Civil and Environmental Engineering, Georgia Institute of Technology, 790

Atlantic Dr., Atlanta, GA 30332-0355, USA

${ }^{\mathrm{b}}$ Department of Materials Science and Engineering, The University of Sheffield, Sir Robert Hadfield Building, Mappin Street, Sheffield, S1 3JD, United Kingdom

${ }^{c}$ Department of Civil and Structural Engineering, The University of Sheffield, Sir Frederick Mappin Building, Mappin Street, Sheffield, S1 3JD, United Kingdom

Email addresses: C.R. Shearer (chris.shearer@sdsmt.edu), J.L. Provis (j.provis@sheffield.ac.uk), S.A.Bernal (s.bernal@sheffield.ac.uk), K.E. Kurtis (kimberly.kurtis@ce.gatech.edu)

*Corresponding author, Phone: +1 (605) 394-2268

${ }^{1}$ Present address: Department of Civil and Environmental Engineering, South Dakota School of Mines and Technology, 501 E. Saint Joseph St., Rapid City, SD 57701, USA 


\begin{abstract}
Co-fired fly ash, derived from the co-combustion of coal and biomass, is examined as a potential precursor for geopolymers. Compared to a coal fly ash, two co-fired fly ashes have a lower vitreous content and higher carbon content, primarily due to differing combustion processing variables. As a result, binders produced with these co-fired fly ashes have reduced reaction potential. Nevertheless, compressive strengths are generally highest for all ashes activated with solutions with a molar ratio of $\mathrm{SiO}_{2} /\left(\mathrm{Na}_{2} \mathrm{O}+\mathrm{K}_{2} \mathrm{O}\right)=1$, and these mixes reach the highest extent of reaction among those studied. Activation with sodium hydroxide solution forms zeolitic phases for all ashes. The thermal and dilatometric behavior of the coal and co-fired fly ash geopolymers is similar between equivalent mix designs. These results indicate that co-fired fly ashes can be viably used to form alkali-activated geopolymers, which is a new beneficial enduse for these emerging waste materials.
\end{abstract}

Keywords: Fly ash, Biomass, Geopolymer, Strength, Characterization, Microscopy

\title{
1. Introduction
}

The practice of co-firing coal with biomass has increased worldwide as a result of stricter emissions regulations and legislation, because biomass combustion can be considered a $\mathrm{CO}_{2-}$ neutral process when the amount of $\mathrm{CO}_{2}$ released into the atmosphere is less than or equal to the amount of $\mathrm{CO}_{2}$ taken up by the plants during their lifetime [1]. In the U.S., biomass electricity generation is expected to increase by an average of $3.1 \%$ each year through 2030 , primarily by co-firing biomass at existing coal power plants [2]. As more coal power plants convert to cofiring, it is critical for industries that beneficially reuse coal fly ash to recognize and understand the potential implications of these changing combustion practices on the quality of fly ash. The 
concrete industry is currently the primary user of coal fly ash as a supplementary cementitious material, but co-fired fly ash — which is the main by-product of the co-firing process — is not currently addressed in the U.S. standard for fly ash use in concrete, ASTM C618-12a [3]. However, co-fired fly ash is permitted for use in concrete with additional restrictions under the European standard (EN 450-1) [4]. Research to find other pathways to utilize this emerging waste stream is undoubtedly warranted, given its projected increase in production in place of pure coal fly ash in many countries [5].

One potential reuse application is to generate alkali-activated geopolymers, which are sustainable binders that can be used as a cost-effective and durable alternative to portland cement concrete [6]. Since coal fly ash is one of the main precursors used for alkali-activated geopolymer production, this research examines the use of co-fired fly ash-which can have comparable chemical compositions and physical properties to coal fly ash—for geopolymerization. The influence of co-firing on geopolymer gel properties is relatively unknown. One study examined the zeolitic formation in two alkali-activated co-fired fly ashes (produced by firing coal with sunflower hulls and an unknown biomass) [7], while another study geopolymerized co-fired fly ash derived from the combustion of a blend of coal, wood and palm pits, with addition of blast furnace slag, to produce high strength mixes [8]. Pure biomass ash from the combustion of eucalyptus forest waste was also successfully geopolymerized, but the strengths of the resulting geopolymer products were relatively low [9].

Co-firing can yield fly ashes with reduced glassy phase content and higher phosphate, alkali and magnesium levels compared to coal fly ash [10], depending on the biomass source and combustion conditions. Biomass ash compositions are also more variable than coal fly ashes (i.e., biomass ashes have a wider distribution of chemical and physical characteristics) [11]. This 
is important because biomass ash constitutes part of the co-fired fly ash, and its variability may present challenges when developing viable geopolymer mix designs. Moreover, many of the coal power plants initially being converted to co-firing facilities in the U.S. are smaller and less efficient, which could result in ashes with a higher unburned carbon content ultimately affecting their suitability for alkali-activation. However, this may not be an issue when more efficient processes are used during co-firing. Since the composition of the precursor material has a significant impact on the reaction potential and formation of geopolymeric products [6], more research is needed to understand the implications of co-firing on the properties of geopolymer binders.

In this study, three ashes — one commercial-quality coal fly ash and two co-fired fly ashes produced by burning coal with wood chips-were alkali-activated and examined using strength testing, infrared spectroscopy, X-ray diffraction (XRD), thermogravimetric analysis (TGA), dilatometry and scanning electron microscopy (SEM). Co-fired fly ash properties are linked to binder properties to better understand how potential changes in their composition may impact the fundamental characteristics of geopolymers. This research is necessary before co-fired fly ashes can be utilized in future low-carbon infrastructure, and is important for understanding the future of geopolymer technology as the U.S., Europe and other regions move increasingly to biomass co-firing as a fuel source for electricity generation and as the availability of coal fly ash decreases.

\section{Experimental Methods}

\subsection{Materials}

Three different ash samples were alkali-activated in this study, one derived from ordinary coal combustion and two derived from co-firing (i.e., produced from the co-combustion of coal 
and biomass during full-scale trials). The sample names in Table 1 use the general notation " $\mathrm{X}$ YA-\#\#", where "X" is the plant at which the sample was produced, "YA" is the type of ash (i.e., FA is coal fly ash and CA is co-fired fly ash) and "\#\#” indicates the replacement percentage (by weight) of coal with biomass in the wet feedstock. B-CA-4 and C-CA-15 were produced by cofiring bituminous coal with pine chips and coarse hardwood chips, respectively. A-FA-0 is a commercially available coal fly ash produced by firing bituminous coal. The elemental compositions of these ashes are listed in Table 2, and were measured by X-ray fluorescence (XRF) on a Philips PW-2400 instrument. Loss on ignition (LOI) was determined gravimetrically using a LECO TGA 601. The ash median particle sizes and particle size distributions shown in Figure 1 were obtained by dry-dispersion laser diffraction (Sympatec RODOS T4.1 Particle Size Analyzer). The Brunauer-Emmett-Teller specific surface area (BET SSA) of each ash was measured by nitrogen adsorption at 77K using a Micromeritics ASAP 2020 Physisorption Analyzer. XRD results measured with a Bruker D8 using an internal standard (rutile) were quantified by the Rietveld method [12]. Total organic carbon content was measured with a Shimadzu TOC analyzer. These properties are listed in Table 2.

All three ash samples are consistent with the category of Class F ashes under ASTM C618 on the basis of their primary oxide contents (i.e., the sum of $\mathrm{SiO}_{2}, \mathrm{Al}_{2} \mathrm{O}_{3}$ and $\mathrm{Fe}_{2} \mathrm{O}_{3}$ is greater than $70 \%$ ). $\mathrm{B}-\mathrm{CA}-4$ has $4 \% \mathrm{CaO}$, which is the highest among these ashes. A-FA-0 has the highest aluminosilicate and amorphous content, which indicates it is primarily composed of a glassy phase. B-CA-4 and C-CA-15 have high carbon contents, which for C-CA-15 is above the 6\% limit stipulated in ASTM C618. B-CA-4 and C-CA-15 also have a lower amorphous glassy content compared to A-FA-0, after subtracting the amorphous phase associated with organic carbon in these ashes. Previous work in characterization of these ashes found that the major 
differences observed here (especially with regard to the alumina, silica and carbon content) are more a function of production variables (e.g., pulverization process, oxygen levels and furnace temperature) and the raw coal properties, rather than the biomass properties $[13,14]$. The carbon content is also the main parameter controlling surface area in these ashes, because the residual carbon has a very high specific surface area.

However, the biomass addition does impact some fly ash characteristics. For example, biomass co-firing seems to have increased the phosphate levels of these ashes compared to coalonly combustion. Additionally, the morphology of the ash may be slightly changed due to the inclusion of fibrous biomass particles intermixed with the mostly spherical coal fly ash particles [14]. Other investigations have found that co-firing can also increase alkali levels when using certain biomass sources [15], which for the purpose of geopolymer manufacture could prove beneficial by increasing the available alkalis in the system. However, biomass co-firing was not found to increase the alkali content of the co-fired fly ashes in this study. It is likely that the quality of these ashes was less affected by co-firing because the use of most woody biomass as a secondary fuel has less of an impact on ash composition compared to other biomass types such as husks and shells [15]. A more in-depth discussion on the production and characteristics of the coal and co-fired fly ashes used in this study can be found in [5].

Table 1: Fly ash nomenclature

\begin{tabular}{lccc}
\hline Sample name & A-FA-0 & B-CA-4 & C-CA-15 \\
\hline Combustion plant & A & B & C \\
\hline Ash type & Coal & Co-fired & Co-fired \\
\hline Coal type & Bituminous & Bituminous & Bituminous \\
\hline Biomass type & - & Pine chips & Coarse hardwood \\
\hline Biomass weight percentage $(\%)$ & 0 & 4 & 15 \\
\hline
\end{tabular}


Table 2: Fly ash properties

\begin{tabular}{|c|c|c|c|}
\hline Composition (\%) & A-FA-0 & B-CA-4 & C-CA-15 \\
\hline Loss on ignition (LOI) & 1.4 & 5.5 & 15.0 \\
\hline TOC & 1.1 & 4.6 & 13.6 \\
\hline $\mathrm{SiO}_{2}$ & 55.3 & 42.8 & 47.1 \\
\hline $\mathrm{Al}_{2} \mathrm{O}_{3}$ & 27.2 & 26.2 & 23.1 \\
\hline $\mathrm{Fe}_{2} \mathrm{O}_{3}$ & 8.0 & 13.9 & 8.7 \\
\hline$\Sigma\left(\mathrm{SiO}_{2}+\mathrm{Al}_{2} \mathrm{O}_{3}+\mathrm{Fe}_{2} \mathrm{O}_{3}\right)$ & 90.5 & 82.9 & 78.8 \\
\hline $\mathrm{CaO}$ & 1.3 & 4.0 & 0.8 \\
\hline $\mathrm{MgO}$ & 1.2 & 1.2 & 0.8 \\
\hline $\mathrm{SO}_{3}$ & 0.1 & 0.4 & 0.1 \\
\hline $\mathrm{Na}_{2} \mathrm{O}$ & 0.5 & 0.5 & 0.3 \\
\hline $\mathrm{K}_{2} \mathrm{O}$ & 3.0 & 2.1 & 2.2 \\
\hline $\mathrm{Na}_{2} \mathrm{O}_{\text {eq }}$ & 2.5 & 1.9 & 1.7 \\
\hline $\mathrm{P}_{2} \mathrm{O}_{5}$ & 0.2 & 0.7 & 0.5 \\
\hline $\mathrm{TiO}_{2}$ & 1.4 & 1.3 & 1.4 \\
\hline $\mathrm{Mn}_{2} \mathrm{O}_{3}$ & 0.1 & 0.1 & 0.0 \\
\hline $\mathrm{Cr}_{2} \mathrm{O}_{3}$ & 0.1 & 0.1 & - \\
\hline Sum total of XRF & 99.6 & 98.8 & 99.9 \\
\hline Moisture content & 0.2 & 0.3 & 0.5 \\
\hline Median particle size $(\mu \mathrm{m})$ & 16.2 & 26.9 & 11.4 \\
\hline $\operatorname{BET~SSA~}\left(\mathrm{m}^{2} / \mathrm{g}\right)$ & 1.3 & 2.5 & 6.1 \\
\hline \multicolumn{4}{|c|}{ Rietveld quantification of XRD data (\%) } \\
\hline Quartz & 14.1 & 10.5 & 10.6 \\
\hline Mullite & 17.4 & 26.5 & 20.6 \\
\hline Iron oxide crystalline phases & 1.1 & 6.1 & 2.5 \\
\hline Amorphous content (total) & 67.5 & 56.9 & 66.3 \\
\hline Amorphous content (excluding carbon) & 66.4 & 52.3 & 52.7 \\
\hline
\end{tabular}

\subsection{Mix Development}

Geopolymer pastes were prepared by mixing three ashes (A-FA-0, B-CA-4 and C-CA15) with six types of alkaline activating solutions. These solutions represent a range of 
commonly used activator compositions with varying silica contents and two cation types (Na and K). Aqueous hydroxide solutions were prepared with either sodium hydroxide pellets or potassium hydroxide pellets to form $\mathrm{Na}_{2} \mathrm{O} \cdot 11 \mathrm{H}_{2} \mathrm{O}$ and $\mathrm{K}_{2} \mathrm{O} \cdot 11 \mathrm{H}_{2} \mathrm{O}$, respectively. Silicate activating solutions were prepared by dissolving amorphous silica in the hydroxide solutions to form either $\mathrm{Na}_{2} \mathrm{O} \cdot 2 \mathrm{SiO}_{2} \cdot 11 \mathrm{H}_{2} \mathrm{O}$ or $\mathrm{K}_{2} \mathrm{O} \cdot 2 \mathrm{SiO}_{2} \cdot 11 \mathrm{H}_{2} \mathrm{O}$. The activator solutions are labelled by the general notation "Z-Ms-\%", where "Z" is the cation type, "Ms" is the modulus of solution (i.e., molar ratio $\left.\mathrm{SiO}_{2} /\left(\mathrm{Na}_{2} \mathrm{O}+\mathrm{K}_{2} \mathrm{O}\right)\right)$ and "\%" indicates the activator concentration by mass of fly ash expressed in terms of equivalent $\mathrm{Na}_{2} \mathrm{O}$ concentration. Note that the hydroxide and silicate solutions with the same cation were mixed to form a solution with an intermediate $\mathrm{Ms}=1$. A constant activator dose of $7 \% \mathrm{Na}_{2} \mathrm{O}$, or equivalent molar content of $10.61 \% \mathrm{~K}_{2} \mathrm{O}$, by mass of fly ash was used for all ashes. An activator dose of $10 \% \mathrm{Na}_{2} \mathrm{O}$ (or equivalent $15.16 \% \mathrm{~K}_{2} \mathrm{O}$ ) by mass of fly ash was also used for the B-CA-4 ash. Pastes made using B-CA-4 and C-CA-15 had less workability due to the higher carbon contents of these ashes, and thus required a higher water/fly ash binder (w/b) ratio (0.4) compared to A-FA-0 (0.25) to develop similar workability as observed empirically. The $\mathrm{w} / \mathrm{b}$ ratio indicates the total mass of water in the mix (including water in the activator solution) divided by the mass of the fly ash. A hardened geopolymer paste was only produced using the Na-1-7 and K-1-7 activating solutions for the C-CA-15 ash.

\subsection{Strength Testing}

Mortars of alkali-activated ash geopolymers were prepared to assess compressive strength. The mortars were cast by mixing fly ash and sand (ash/sand mass ratio of 0.5 ) with activator solution for $12 \mathrm{~min}$. The mix designs for the mortars are shown in Table 3 . Note that the geopolymer pastes used in this study have the same composition as these mortars, but 
without sand. Six $50.8 \mathrm{~mm}$ cubes per mix were cast on a vibration table and placed in a moist environment for curing maintained at $40^{\circ} \mathrm{C}$ for 7 days prior to compressive strength testing.

Table 3: Mortar mix designs for strength testing

\begin{tabular}{|c|c|c|c|c|c|c|}
\hline Activator type & Fly $\operatorname{Ash}^{1}(\mathrm{~g})$ & Sand $(\mathrm{g})$ & $\begin{array}{l}\text { Hydroxide } \\
\text { Solution }^{2}(\mathrm{~g})\end{array}$ & $\begin{array}{c}\text { Silicate } \\
\text { Solution }^{2}(\mathrm{~g})\end{array}$ & $\begin{array}{l}\text { Added Water } \\
\text { for A-FA-0 }(\mathrm{g})\end{array}$ & $\begin{array}{l}\text { Added Water for } \\
\text { B-CA-4 and C- } \\
\text { CA-15 (g) }\end{array}$ \\
\hline $\mathrm{Na}-0-7$ & 600.0 & 1200.0 & 176.1 & 0.0 & 15.9 & 105.9 \\
\hline Na-1-7 & 600.0 & 1200.0 & 88.1 & 128.7 & 15.9 & 105.9 \\
\hline $\mathrm{Na}-2-7$ & 600.0 & 1200.0 & 0.0 & 257.4 & 15.9 & 105.9 \\
\hline K-0-7 & 600.0 & 1200.0 & 197.8 & 0.0 & 15.9 & 105.9 \\
\hline K-1-7 & 600.0 & 1200.0 & 98.9 & 139.5 & 15.9 & 105.9 \\
\hline $\mathrm{K}-2-7$ & 600.0 & 1200.0 & 0.0 & 279.1 & 15.9 & 105.9 \\
\hline Na-0-10 & 600.0 & 1200.0 & 251.6 & 0.0 & - & 48.4 \\
\hline Na-1-10 & 600.0 & 1200.0 & 125.8 & 183.9 & - & 48.4 \\
\hline $\mathrm{Na}-2-10$ & 600.0 & 1200.0 & 0.0 & 367.7 & - & 48.4 \\
\hline K-0-10 & 600.0 & 1200.0 & 282.6 & 0.0 & - & 48.4 \\
\hline $\mathrm{K}-1-10$ & 600.0 & 1200.0 & 141.3 & 199.4 & - & 48.4 \\
\hline $\mathrm{K}-2-10$ & 600.0 & 1200.0 & 0.0 & 398.7 & - & 48.4 \\
\hline
\end{tabular}

${ }^{\mathrm{I}}$ A-FA-0, B-CA-4 or C-C-15 fly ash (only B-CA-4 was mixed with $10 \% \mathrm{Na}_{2} \mathrm{O}_{\text {eq }}$ solutions)

${ }^{2} \mathrm{Na}$ or $\mathrm{K}$ solutions as indicated by the activator type

\subsection{Characterization of Reaction Products}

Geopolymer paste specimens were cast in sealed cylindrical molds and cured at $40^{\circ} \mathrm{C}$ until analysis. Fourier transform infrared (FTIR) spectrometry was conducted on the ashes and on all pastes to evaluate the degree of polymerization of the pastes after alkali-activation.

Measurements were taken after 7 and 28 days of curing using the $\mathrm{KBr}$ pellet technique with a Bruker TENSOR instrument, scanning from 1300 to $400 \mathrm{~cm}^{-1}$ with a resolution of $2 \mathrm{~cm}^{-1}$. XRD was performed on the ashes and on pulverized samples of each geopolymer paste after 28 days of curing to detect the formation of crystalline zeolites after alkali-activation. Diffractograms were recorded under $\mathrm{Cu} \mathrm{K \alpha}$ radiation from $3-70^{\circ} 2 \theta$ in $0.02^{\circ} 2 \theta$ increments with a count time of $4 \mathrm{~s}$ 
per step, using a Bruker D8 ADVANCE diffractometer. Gold-sputtered fly ash and geopolymer pastes were examined in a Zeiss Ultra60 FE-SEM (field-emission scanning electron microscope) at varying magnifications under high vacuum with an accelerating voltage of $5 \mathrm{kV}$ to observe the geopolymer binder development.

\subsection{Thermogravimetric Analysis (TGA)}

TGA was performed on geopolymer paste samples to assess the water environments within these materials. Samples were cast in a sealed syringe and cured at $40^{\circ} \mathrm{C}$ for 7 days. A fraction of each paste was pulverized into a fine powder after curing. Acetone was used to stop the reaction, and then removed by filtration. The powder $(10-20 \mathrm{mg})$ was placed in a platinum pan in a Hitachi TG/DTA 7300 instrument under a constant flow of nitrogen gas. The sample was heated from $25-1100^{\circ} \mathrm{C}$ at a rate of $10^{\circ} \mathrm{C} / \mathrm{min}$, and the change in mass was recorded as a function of temperature.

\subsection{Thermomechanical Analysis (TMA)}

Dilatometry was performed on geopolymer paste samples to provide information regarding their gel and pore structures. Samples were cast in a sealed syringe and cured at $40^{\circ} \mathrm{C}$ for 7 days. Cylinders approximately $5 \mathrm{~mm}$ in diameter and $10 \mathrm{~mm}$ long were cut and tested in a PerkinElmer Diamond Thermomechanical Analyzer. Each sample was held at $30^{\circ} \mathrm{C}$ for $10 \mathrm{~min}$ and then heated to $1000^{\circ} \mathrm{C}$ at $10^{\circ} \mathrm{C} / \mathrm{min}$ under a nitrogen gas purge and a constant load of $50 \mathrm{mN}$ to hold the specimen in place. The longitudinal deformation of the specimen was recorded as a function of temperature. 


\section{Results and Discussion}

\subsection{Compressive Strength}

Compressive strength values are plotted in Figure 2 as a function of the modulus of solution for all alkali-activated mortars. The ash source and activator type both had a significant impact on the mechanical properties of the formed geopolymers. The activators with Ms $=1$ produced the strongest mixes overall for all ashes, and the high-quality coal fly ash (A-FA-0) mixes had the highest strengths of any ash (up to $78 \mathrm{MPa}$ ) at this modulus. The impact of the ash composition on strength was also most significant at $\mathrm{Ms}=1$. At Ms $=2$, the co-fired fly ash BCA-4 actually had a higher strength than the coal fly ash A-FA- 0 , highlighting that achieving optimal geopolymer mix performance requires the appropriate combination of ash and activator.

The variation in strengths between the alkali-activated ash mortars was likely affected by the differing chemical and physical properties of the precursor. For example, A-FA-0 is finer than B-CA-4, and has a lower unburned carbon content, which may have increased its reactivity and strength at Ms $=1$. However, the reactive amorphous content of the ashes was likely more significant in determining strength. The higher glassy aluminosilicate content of A-FA-0 compared to both B-CA-4 and C-CA-15 contributed to its high strength after activation with certain alkali solutions, since the vitreous silica- and alumina-rich phases in coal fly ash contribute the most to the formation of geopolymer products [16]. As a result, C-CA-15 produced much weaker gels compared to A-FA-0 even though C-CA-15 is the finest ash. It is likely that the differences in fineness and the lower vitreous content of the co-fired fly ashes are more related to the composition of the parent coal and combustion conditions and less a result of co-firing with wood, as indicated by the similar overall physical and chemical characteristics of coal fly ashes produced at the same plant under similar processing conditions to the co-fired fly 
ashes used in this study $[13,14]$. The co-fired fly ashes used in this study are primarily comprised of ash derived from the coal combustion with a much smaller quantity of ash derived from the secondary wood fuel source. For both of these co-fired fly ashes, the biomass ash constitutes at most around $1 \%$ as calculated from the ash contents of the biomass and coal fuels [5].

The high unburned carbon content in the co-fired fly ashes reduced their reactive potential and contributed to the higher water demand of these mixes. Additionally, the residual carbon could have behaved like an alkali sink by adsorbing — and effectively removing — alkali cations necessary for the geopolymeric reaction [17]. As a result, the ash with the highest carbon content (C-CA-15) did not form a hardened geopolymer gel at Ms $=0$ or 2 (plotted at zero strength) even though it had a slightly higher glassy content than B-CA-4, which formed hardened gels at all Ms values. Also, the higher calcium content of B-CA-4 may have contributed to its higher strength at $\mathrm{Ms}=2$ (relative to both C-CA-15 and A-FA-0), because a greater concentration of alkaline earth metals such as calcium in the precursor has been shown to increase geopolymer strength [18].

For these ashes, Na-activated mixes were generally stronger than equivalent K-activated mixes. The K-activators may have been less effective in breaking down the amorphous content of the co-fired fly ashes and also retarded the reaction kinetics compared to the Na-activators for some mixes, which is similar to their effect on coal fly ash during activation $[19,20]$. Still, it appears the silica content of the activation solution had a greater impact on strength than cation type. For the coal and co-fired fly ashes the optimum modulus of solution for strength was 1 among the activator solutions tested. Geopolymers too poor or rich in silica tend to have low strengths [21], which could explain why both the coal and co-fired fly ashes produced mixes 
with similarly low strengths at Ms $=0$ and 2 (although for B-CA-4 the difference in strength between Ms values of 1 and 2 is much lower than for A-FA- 0 and C-CA-15). Also, for B-CA-4 mixes an increase in activator concentration from $7 \%$ to $10 \%$ had the greatest effect on strength at $\mathrm{Ms}=1$. B-CA-4 Na-1-10 was the strongest co-fired fly ash mix overall, with a binder strength of $44 \mathrm{MPa}$, sufficient for many applications.

\subsection{Infrared Spectroscopy}

FTIR spectra are shown in Figure 3 for both the raw ashes and the geopolymer pastes cured for 7 days. The peaks of key interest are the bending and stretching modes of the Si-O-T bonds, where $\mathrm{T}$ is either $\mathrm{Si}$ or $\mathrm{Al}$ in tetrahedral coordination. All three ashes have a wide and intense peak between 1069-1074 $\mathrm{cm}^{-1}$ associated with the asymmetric stretching of the Si-O-T bonds (the main Si-O-T peak). There is also a shoulder visible between $1159-1167 \mathrm{~cm}^{-1}$ in these ash spectra, linked to the asymmetric Si-O-Si stretching vibration. Quartz bands were detected as a doublet at 793-797 and $777 \mathrm{~cm}^{-1}$, and peaks at $694-696 \mathrm{~cm}^{-1}$ and $453-461 \mathrm{~cm}^{-1}$, for all three raw ashes, and a wide band representing mullite was observed between $550-554 \mathrm{~cm}^{-1}$ [22]. The bands around the $450 \mathrm{~cm}^{-1}$ region are also associated with the internal deformation vibrations of the TO bonds, also known as the in-plane bending mode [23]. The similar locations of these bands for all three ashes indicate that both co-fired fly ashes have a comparable aluminosilicate molecular structure to the coal fly ash.

After alkali-activation, the main Si-O-T peak shifted to a lower wavenumber after 7 days of curing for all coal and co-fired fly ashes due to the incorporation of $\mathrm{Al}$ and/or substitution of the alkali metal cations into the network, and the higher concentration of non-bridging oxygen atoms in the partially formed geopolymer compared to the raw ash [19, 24]. The original, glassy tetrahedral silicate and/or aluminosilicate framework of the coal and co-fired fly ashes was 
partially depolymerized, and a new aluminosilicate geopolymer gel was subsequently

polymerized. The quartz and mullite bands did not significantly shift after alkali-activation, indicating that these crystalline phases remained unchanged.

The silica content of the activator solution had the most significant impact on the main Si-O-T peak shift. Ms $=0$ mixes underwent the largest shift to the lowest wavenumber, while the silicate activators (both $\mathrm{Ms}=1$ and 2) produced more highly polymerized gels for all three ashes as indicated by the higher wavenumbers in this region. For coal fly ash gels, the $\mathrm{pH}$ and silicate speciation are responsible for controlling the degree of polymerization [25-27]. Speciation appears to also control polymerization in co-fired fly ash gels. The higher wavenumber position observed for this peak in the silicate-activated mixes is partly a result of their greater repolymerized gel fraction, which correlates well with strength values (i.e., Ms = 1 mixes produced the highest strengths for all three ashes).

The alkali ion type and activator dose also influenced the degree of polymerization of these gels. For mixes with no or less added silica (i.e., Ms $=0$ and 1), the potassium activators tended to shift the primary asymmetric stretching band less than comparable sodium activators, resulting in higher wavenumbers for both the coal and co-fired fly ash gels when using Kactivation. K-activation increases the condensation of aluminosilicate structures during their formation due to the larger size of the $\mathrm{K}^{+}$ion compared to the $\mathrm{Na}^{+}$ion, which results in a more polymerized (but not necessarily stronger) gel [28]. For B-CA-4, an increase in activator dose promoted further dissolution of the original amorphous phase of the co-fired fly ash, which is signified by the lower wavenumbers of the main stretching band for most of the 10\%-activated gels (Figure 3c) compared to equivalent 7\%-activated gels (Figure 3b).

The ash composition also impacted the main peak location, but likely less than the activator composition and concentration for these samples. The glass in the B-CA-4 ash may have been depolymerized to a greater extent by some activating solutions due to its higher 
content of alkaline earth metals (e.g., $\mathrm{Ca}^{2+}$ ), which are network modifiers and promote the dissolution of aluminum [18]. However, the impact of the ash composition on the subsequent repolymerization is less clear from these data. For both co-fired fly ashes, the higher carbon content likely adsorbed some of the alkalis which are necessary for the reorganization and crosslinking of the leached $\mathrm{Si}$ and $\mathrm{Al}$ species to form N-A-S-H or K-A-S-H gel. Perhaps as a consequence of this and its lower vitreous content, B-CA-4 gels produced at Ms $=1$ were less polymerized after 7 days than corresponding A-FA-0 gels, and also had lower strengths. C-CA15 gels had higher wavenumbers at this band location compared to A-FA-0, but also produced much lower strengths. For C-CA-15 gels, these higher wavenumbers are likely due to the lower initial depolymerization of C-CA-15, and not due to a greater repolymerization.

Changes in the main stretching band directly related to biomass co-firing are more difficult to identify. The increase in $\mathrm{P}_{2} \mathrm{O}_{5}$ content may have altered the depolymerization potential for the co-fired fly ashes because it is a network former [29]. Crystallized phosphate minerals can form within Si-K glass in pure biomass ash [30], but it is not clear whether the additional phosphate from the biomass fuel is present in the glassy reactive phases in these cofired fly ashes. Regardless, the concentration of any impurities added to the ash as a result of cofiring is small relative to the overall aluminosilicate content derived from the coal. It appears from these data that the alkali-activation reaction mechanisms for co-fired fly ash are analogous to those observed for coal fly ash, which is not unexpected given that the majority of the ash is derived from coal combustion.

Figure 4 shows the main Si-O-T peak locations of the geopolymers after 28 days of curing. In general, this wavenumber location was higher for gels with added silica, which was also observed for many of these samples at 7 days. There were slight shifts in the main stretching 
band between 7 and 28 days of curing for most of the gels indicating some change in the crosslinking of their aluminosilicate structure with time. For alkali-activated coal fly ash, a gel that is enriched in Al-containing bonds is initially formed, and eventually replaced with a gel containing more Si-O linkages at later ages [31]. The data show that for most of the coal and co-fired fly ash geopolymers, this secondary gel has likely formed by 7 days, as demonstrated by the relative stabilization of this main band.

\subsection{X-Ray Diffraction}

The coal fly ash A-FA-0 (Figure 5a) primarily contains an X-ray amorphous phase with a smaller quantity of quartz $\left(\mathrm{SiO}_{2}\right.$, Powder Diffraction File (PDF) card 01-083-0539), mullite $\left(\mathrm{Al}_{6} \mathrm{Si}_{2} \mathrm{O}_{13}, \mathrm{PDF}\right.$ 00-015-0776) and a combination of iron oxides. Multiple iron oxide phases with overlapping peaks were observed in this diffractogram, which makes their identification difficult. However, the iron content in the coal fly ash is mostly a ferrite spinel (with substitution of various elements onto both the $\mathrm{Fe}^{2+}$ and $\mathrm{Fe}^{3+}$ sites as previously observed [32]), but may also include some hematite ( $\mathrm{Fe}_{2} \mathrm{O}_{3}$, PDF\# 00-033-0664). The major phase in both B-CA-4 and C-CA15 (Figure 5b-5d) is also X-ray amorphous with similar crystalline phases to the coal fly ash: quartz ( $\mathrm{SiO}_{2}, \mathrm{PDF} \#$ 01-083-0539 for both), mullite ( $\mathrm{Al}_{6} \mathrm{Si}_{2} \mathrm{O}_{13}, \mathrm{PDF}$ 00-015-0776 for both), a ferrite spinel phase, and possibly maghemite $\left(\gamma-\mathrm{Fe}_{2} \mathrm{O}_{3}, \mathrm{PDF}\right.$ 00-089-5894) in B-CA-4, and magnetite ( $\mathrm{Fe}_{3} \mathrm{O}_{4}$, PDF\# 01-078-3149) and hematite ( $\mathrm{Fe}_{2} \mathrm{O}_{3}$, PDF\# 00-033-0664) in C-CA-15. The peaks associated with iron oxide phases are more intense in B-CA-4, which correlates well with the quantitative XRD results in Table 2.

The similarity between the crystalline phases identified in the three raw ashes suggests that the secondary fuel did not noticeably impact the crystalline composition of these co-fired fly ashes. Wood ash typically contains crystalline phases that depend on the species type and 
combustion temperature, but which normally contain calcium, potassium and other trace elements such as phosphates $[13,30,33]$. No calcium, potassium or phosphate-containing crystalline phases were detected in these co-fired fly ashes, which may indicate that the quantity of crystalline phases potentially derived from the wood ash was too low to be detected by XRD. Furthermore, wood ash can have a much lower amorphous content than coal fly ash [13], which is a more important characteristic regarding the usefulness of co-fired fly ash as a precursor material given that wood ash is a component. Still, all three ashes have an amorphous hump at around $15-35^{\circ} 2 \theta$ and centered around $25^{\circ} 2 \theta$. As previously discussed, the co-fired fly ashes have lower glassy amorphous contents compared to the coal fly ash, however this is more likely a result of differences in combustion processing variables than the inclusion of the wood ash.

After alkali-activation, an amorphous aluminosilicate geopolymer gel was formed that is identifiable by a broad peak at a higher angle (around $15-40^{\circ} 2 \theta$ and centered around $28^{\circ} 2 \theta$ ) than the peak due to the vitreous phases in the fly ash. Crystalline zeolitic phases were also formed after activation with $\mathrm{Na}-0$ solutions for all three ashes. For A-FA-0, hydrosodalite $\left(1.08 \mathrm{Na}_{2} \mathrm{O} \cdot \mathrm{Al}_{2} \mathrm{O}_{3} \cdot 1.68 \mathrm{SiO}_{2} \cdot 1.8 \mathrm{H}_{2} \mathrm{O}, \mathrm{PDF}\right.$ 00-031-1271) was identified, along with a hydrous sodium silicate $\left(\mathrm{Na}_{2} \mathrm{Si}_{3} \mathrm{O}_{7} \cdot \mathrm{H}_{2} \mathrm{O}\right.$, PDF\# 01-072-6800). For B-CA-4, activation at $7 \% \mathrm{Na}_{2} \mathrm{O}$ led to the formation of chabazite- $\mathrm{Na}\left(\mathrm{NaAlSi}_{2} \mathrm{O}_{6} \cdot 3 \mathrm{H}_{2} \mathrm{O}\right.$, $\mathrm{PDF} \#$ 00-019-1178), faujasite ( $\mathrm{NaAlSi}_{2} \mathrm{O}_{6} \cdot 4 \mathrm{H}_{2} \mathrm{O}$, PDF\# 00-039-1380), analcime ( $\mathrm{NaAlSi}_{2} \mathrm{O}_{6} \cdot \mathrm{H}_{2} \mathrm{O}$, PDF\# 00-019-1180) and potentially natron $\left(\mathrm{Na}_{2} \mathrm{CO}_{3} \cdot 10 \mathrm{H}_{2} \mathrm{O}\right.$, PDF\# 00-015-0800). When activating B-CA-4 at $10 \% \mathrm{Na}_{2} \mathrm{O}$, all of the zeolites formed at $7 \%$ were again detected except for faujasite, and natron was also detected. It appears that for B-CA-4, an increase in alkali content reduced zeolite formation. Perhaps more of the species necessary for the formation of faujasite were incorporated into the additional amorphous strength-giving gel, as strengths were slightly higher with $10 \% \mathrm{Na}_{2} \mathrm{O}$ 
activation. For C-CA-15, only faujasite was detected. The variation in zeolite formation between binders with similar activators was a result of the different ash compositions, although the chemical compositions of the formed zeolites were similar overall.

No zeolites were detected in any of the K-activated ashes, even at Ms $=0$, because the formation of potassium zeolite structures is not as favored as the formation of sodium zeolites [20]. No additional crystalline phases were detected after activation with any solution with added silica (both $\mathrm{Na}$ and $\mathrm{K}$ ), suggesting that the added alkali ions have either been incorporated into the amorphous gel phase or are still available in the pore solution. Also, an increase in soluble silica has been shown to slow zeolite formation [27], which is consistent with these results.

\subsection{Thermogravimetry}

The thermogravimetric data for the ashes and geopolymer pastes are shown in Figure 6. The bulk of the weight loss for all mixes occurred early in the heating process due to the evaporation of easily accessible free water below $100^{\circ} \mathrm{C}$ in addition to the loss of free water from the gel pores between $100-250^{\circ} \mathrm{C}$. Given the higher water content of the B-CA-4 mixes compared to A-FA-0 mixes ( $/ \mathrm{b}=0.4$ vs. 0.25$)$, evaporation in this region was expected to be greater for B-CA-4 geopolymers due to presence of more available free water. However, equivalent A-FA-0 and B-CA-4 mixes had similar weight loss up to $250^{\circ} \mathrm{C}$. This may be a result of the high residual carbon content of this ash, which can adsorb water on its surface and effectively remove it from the pore system [34]. However, further investigation is needed to better understand the potential of the carbon in these ashes to bind water.

Between $250-600^{\circ} \mathrm{C}$, the weight loss for all pastes was due to dehydroxylation of the gel and subsequent condensation of the bound silanol or aluminol groups [35]. At higher temperatures, distinct weight loss events were likely caused by the decomposition of carbonated 
phases or carbonate salts in the pore solution. Additionally, weight loss associated with the decomposition of the unburned carbon in the raw ashes occurred mostly above $800^{\circ} \mathrm{C}$. Carbon oxidation can still occur in an inert $\mathrm{N}_{2}$ atmosphere, which was used to analyze these samples, due to the reduction of iron oxides at these high temperatures [36]. Weight loss at $800^{\circ} \mathrm{C}$ for the raw B-CA-4 and C-CA-15 ashes were $1.0 \%$ and $2.2 \%$, respectively, which is still significantly lower than their LOI values (5.5\% and $15.0 \%$, respectively) measured under normal atmospheric conditions. The weight loss of the raw low-carbon A-FA- 0 at $800^{\circ} \mathrm{C}$ is $0.8 \%$ which is similar to that found for B-CA-4, and thus the direct comparison of the various geopolymer pastes using TGA is warranted when comparing weight loss below $800^{\circ} \mathrm{C}$.

The total weight loss at $800^{\circ} \mathrm{C}$ of B-CA-4 mixes was higher compared to all equivalent A-FA-0 mixes, but a larger fraction of weight was lost before $250^{\circ} \mathrm{C}$ for A-FA-0 mixes. Comparison of C-CA-15 TGA data with the A-FA-0 and B-CA-4 is more difficult because of the overlapping decomposition of organics with geopolymer-related weight loss. Nevertheless, the total weight losses for C-CA-15 mixes were within the range of those observed for the other two ashes. Overall, the thermal behavior of the co-fired fly ash gels as measured by TGA was similar to that of the coal fly ash gels, suggesting comparable gel and pore structures.

For all pastes, the total weight loss at $800^{\circ} \mathrm{C}$ was higher for Na-activated geopolymers compared to equivalent K-activated geopolymers. This could be a result of the greater amount of geopolymer gel in these binders, which was also evidenced by the higher strengths of the Naactivated geopolymers in general. However, the majority of difference in weight loss between $\mathrm{Na}$ and $\mathrm{K}$ geopolymers occured below $250^{\circ} \mathrm{C}$, which suggests that differences in the availability of free water also played a significant role. Also, total weight losses were higher for A-FA-0 mixes 
with added silica (i.e., Ms = 1 and 2), perhaps due to the higher bound water contents of these gels.

For B-CA-4, an increase in activator content from $7 \%$ to $10 \%$ also increased weight loss at both $250^{\circ} \mathrm{C}$ (by $18-32 \%$ ) and $800^{\circ} \mathrm{C}$ (by 10-24\%). The geopolymers that exhibited an increased strength due to an increased activator content also had a greater total weight loss. It is likely that additional geopolymer gel products were formed in these pastes, resulting in this higher weight loss. For mixes with no added silica $(\mathrm{Ms}=0)$, the increase in total weight loss due to an increased alkali content was lowest, and these mixes correspondingly had the least significant changes in strength due to an increased activator dose.

\subsection{Dilatometry}

The dilatometric curves for the six alkali-activated coal fly ash (A-FA-0) mixes are presented in Figure 7a. The thermal behavior of these pastes is consistent with those observed by others for alkali-activated coal fly ash and metakaolin [35, 37-40]. As evidenced by the TGA data, shrinkage occurred below $250^{\circ} \mathrm{C}$ due to the evaporation of water from the aluminosilicate gel. For A-FA-0, the onset temperature of shrinkage in the $100-250^{\circ} \mathrm{C}$ region was highest for the Ms $=1$ mixes. The high mechanical strengths of these mixes likely provided greater resistance to this initial shrinkage in a way analogous to metakaolin geopolymers with high elastic moduli, which have been shown to better resist capillary strain forces due to pore shrinkage in this temperature region [35]. Between $250-600^{\circ} \mathrm{C}$ there was a more gradual shrinkage in all samples linked to dehydroxylation of the gel, which was also observed by TGA. In this region, the thermal shrinkage was greatest for $\mathrm{Ms}=1$ mixes, suggesting that these gels had a higher bound hydroxyl content due to a higher degree of reaction. 
The thermal behavior of A-FA-0 samples was more varied above $600^{\circ} \mathrm{C}$, which was primarily a function of the activator type. Specifically, the Si content and cation type of the initial solution significantly impacted expansion at higher temperatures. Typically, aluminosilicate geopolymer gels densify due to viscous sintering above $600^{\circ} \mathrm{C}$ [41]. This phenomenon was visible on both K-1 and Na-1 dilatometric traces, but less so in the other traces. This may be due to the greater quantity of gel available for sintering in the Ms $=1$ samples, but also could be attributed to the overlapping expansion observed in this region for some activators, which began around $400^{\circ} \mathrm{C}$ for the $\mathrm{K}-2$ and Na-2 mixes and around $500^{\circ} \mathrm{C}$ for the $\mathrm{K}-0$ mix. For high silicate mixes, this low-temperature expansion has been linked to the foaming of loosely bound water associated with the high amounts of unreacted silica in the gel [39]. A similar phenomenon may have occurred in the K-0 activated gel; water might have foamed from the release of hydroxyls bound on depolymerized $\mathrm{Q}^{3}, \mathrm{Q}^{2}$ or $\mathrm{Q}^{1}$ sites, which are more common in less-polymerized geopolymers such as this one (as evidenced by its low main Si-O-T band wavenumber detected by FTIR) [39, 42]. On the other hand, the Na-0 gel remained relatively stable over this temperature range (i.e., no expansion was observed at lower temperatures) indicating that it had a comparatively more cross-linked gel. Another expansion at even higher temperatures was detected in all mixes, although this expansion peak was obscured for some samples by a more pronounced concurrent shrinkage. This has been associated with the liberation of chemically bound water from an undercoordinated silica-rich gel phase, and could potentially be correlated to strength [37, 39], as will be further discussed later in this section. Lastly, all of the mixes experienced significant shrinkage above $1000^{\circ} \mathrm{C}$ due to further melting of the binder. 
Co-fired fly ash (B-CA-4) gels exhibited a similar thermal behavior compared to corresponding coal fly ash gels (Figure 7b). In the low-temperature region associated with the dehydration of pores (up to $250^{\circ} \mathrm{C}$ ), shrinkage was comparable depending on the activating mix, which corresponds well with evaporation measured by TGA. These gels were produced with a higher $\mathrm{w} / \mathrm{b}$ ratio compared to A-FA-0 and thus might be expected to have greater shrinkage in this region. However, shrinkage was largely unaffected because water in very large pores, which will be more notable at higher $\mathrm{w} / \mathrm{b}$, will cause less shrinkage during evaporation. Also similar to the coal fly ash gels, the onset shrinkage temperature in this region was highest for mixes with the highest mechanical strength (i.e., Na-1-7 and K-1-7).

Within the dehydroxlation region, one high-silica mix (K-2-7) began expanding due to the foaming of loosely bound water associated with the high-silica gel. However, compared to the equivalent A-FA- 0 mix, the expansion of this paste began at a higher temperature $\left(\sim 500^{\circ} \mathrm{C}\right)$ and was less intense. Moreover, the B-CA-4 Na-2-7 mix did not expand at low temperatures, unlike the equivalent A-FA- 0 mix. This suggests that the B-CA-4 mixes contain less of the expansive silica phase than the A-FA-0 mixes when activated at $\mathrm{Ms}=2$, as the additional silica has been incorporated into further geopolymer formation. This is also substantiated by the similar or higher strengths at $\mathrm{Ms}=2$ compared to $\mathrm{Ms}=1$ for this ash at the $7 \%$ activator dose. Increasing the alkali content from $7 \%$ to $10 \%$ for B-CA-4 significantly affected the dilatometric traces (Figure 7c). Overall, 10\% activated pastes exhibited less dimensional stability upon heating, in agreement with previous results for coal fly ash alkali-activation [37]. Na-1-10 appears to be the only mix in this series which was able to better resist the early pore collapse caused by loss of the free water compared to corresponding $7 \%$ mixes. Na-1 was also the only activator for B-CA-4 that resulted in a substantial increase in strength due to a higher alkali dose. 
Shrinkage due to loss of bound hydroxyls was similar for both activator concentrations, but the expansion and shrinkage features at higher temperatures were more exaggerated at the $10 \%$ activator dose.

For both ashes, K-geopolymers had less thermal shrinkage than Na-geopolymers at each respective Ms value. The lower shrinkage for K-geopolymers was particularly evident in the dehydration region where K-activation also exhibited less weight loss compared to Naactivation, but less evident during dehydroxylation. Cation type also had an impact on the viscous sintering onset temperature for these mixes; sintering of K-geopolymers tended to take place at higher temperatures compared to Na-geopolymers. This is most discernible in pastes where expansion due to silica-rich phases is not superimposed on viscous sintering shrinkage. Shrinkage can also be influenced by crystallization in the geopolymer gel at temperatures above $650^{\circ} \mathrm{C}$ [43]. For coal fly ash geopolymers, the decomposition of the gel can result in the formation of $\mathrm{Na}$ and $\mathrm{K}$ feldspars at elevated temperatures, although crystallization is more favored in Na-geopolymers due to the higher diffusion coefficient of Na compared to K upon heating [44]. It is possible that crystallization in the Na-geopolymers (especially for B-CA-4) could be responsible for some of the expansion observed over the thermal evolution due to crystallization pressure cracking. However, for most of these mixes, it is likely that the overall thermal behavior at these high temperatures is controlled more by the viscous flow of the amorphous gel phase [43].

C-CA-15 had nearly identical dilatometric curves for K-1-7 and Na-1-7 (Figure 7d), which was not observed for A-FA-0 and B-CA-4. Since C-CA-15 mixes had the least variation in strength between cation types at Ms $=1$ when comparing all three ashes (i.e, the strength of Na-1-7 was only $19 \%$ more than K-1-7), the structure of the geopolymer gel may be more 
similar for this ash when using these activators. This suggests that the alkali cation type had less of an effect on gel formation for this ash. Regardless, both of the pastes formed with C-CA-15 had high dimensional stability, and pore shrinkage was greater than any expansive processes at all temperatures.

\subsubsection{Relationship between expansion onset temperature and strength}

Previous work has correlated the onset temperature of the primary high-silica gel expansion peak to compressive strength for coal fly ash geopolymers, with higher onset temperatures linked to stronger binders $[37,39]$. To enable these comparisons, the first and second derivatives of each dilatometric curve were plotted to easily detect the onset temperature of this reaction for each gel (i.e., the second derivative has a maximum at the location of the onset of this expansion peak). The derivative curves were determined using numerical differentiation based on Tikhonov regularization [45], which incorporates smoothing techniques to mitigate the inherent scatter in the numerical data upon differentiation. An example of the derivative curves for the A-FA-0 Na-1-7 mix is shown in Figure 8, with the expansion peak of interest marked.

The onset temperatures for this expansion peak are plotted vs. strength results for all Naactivated gels in Figure 9a, and for all K-activated gels in Figure 9b. Generally, stronger geopolymers exhibited higher onset temperatures for both cation types (as previously observed $[37,39])$, but the correlation is stronger for K-activated gels compared to Na-activated gels. This could be due to the presence of discrete sodium silicate hydrates, such as those detected by XRD for some mixes, which can crystallize in sodium silicate activator solutions with Ms values similar to those used in these samples [46]. During heating, these unreacted crystalline components may also foam, causing expansion at temperatures which are inconsistent with 
expansion peak temperatures typically correlated to strength-giving gels. Conversely, Kactivation creates a more homogeneous gel (i.e., no discrete silicate crystals), and the primary high-silica gel expansion peak is more clearly defined. Consequently, the correlation of these peaks with strength is better for $\mathrm{K}$ than for Na. Regardless, these results confirm that this technique can potentially be used as a quick screening tool to assess the viability of ashes for alkali-activation, whether co-fired or derived from pure coal combustion.

\subsection{Geopolymer Gel Microstructure}

SEM images of the three raw ashes used in this study are shown in Figure 10. A-FA-0 has mainly spherical particles, which is the characteristic morphology of the largely glassy fraction of coal fly ash. Biomass ash produced from pure wood combustion has a significantly different morphology compared to coal fly ash; it is mostly composed of fibrous particles with intact cell wall structures and high aspect ratios in addition to agglomerated fused woody particles [13]. In the B-CA-4 co-fired fly ash, an elongated particle can be seen intermixed with spherical particles that are more typically observed in coal fly ash. This elongated particle has a similar morphology to biomass ash and could be a result of co-firing, although unburned carbon particles in coal fly ash can also be elongated [14]. In the C-CA-15 co-fired ash, both elongated particles and amorphous unburned carbon particles were observed in addition to spherical particles.

SEM images of Na-activated B-CA-4 pastes are shown in Figure 11. When activated with Na-0-10, the paste had a porous microstructure that contained a large amount of unreacted or partially-reacted particles (mostly spherical) embedded in the gel. Elongated particles were not detected in the geopolymer gels imaged in this study, most likely because these particles are scarce and thus not visible on these fractured surfaces. Regardless, B-CA-4 is predominantly 
composed of amorphous aluminosilicates and Fe-rich particles, as evidenced by XRF and XRD. The glassy phases of B-CA-4 reacted with Na-0-10 to form a visually heterogeneous gel.

Compared to Na-0-10 activation of this co-fired fly ash, Na-1-10 formed a more visually homogenous gel structure with a denser, less porous matrix and fewer unreacted or partiallyreacted particles. Na-2-10 activation also produced a more homogeneous gel compared to Na-010, but more unreacted particles remained embedded in the matrix compared to Na-1-10. Silicate-activated coal fly ash geopolymers have also been shown to have a more homogeneous microstructures compared to hydroxide-activated geopolymers as a result of the different reaction mechanisms that occur during the gelation process when comparing the two types of activators [47].

SEM images of K-activated B-CA-4 pastes are shown in Figure 12. The microstructures of the K-1-10 and K-2-10 gels were similar to Na-1-10 and Na-2-10, respectively, on the same length-scale. That is, K-1-10 had a mostly uniform microstructure whereas the microstructure of K-2-10 was less homogeneous. K-0-10 activation formed much less gel product compared to both Ms $=1$ and 2 activation, resulting in a more porous binder with a greater amount of unreacted particles even compared to Na-0-10. The trends observed at these scales between silicate and hydroxide activation were also evident at much lower magnifications (i.e., Ms $=1$ and 2 activation formed denser binders than $\mathrm{Ms}=0$ ). Comparison of the observed microstructures for the co-fired fly ash binders with the strength results (where the strengths were ranked Na-1-10 $>\mathrm{K}-1-10>\mathrm{Na}-2-10>\mathrm{K}-2-10>\mathrm{Na}-0-10>\mathrm{K}-0-10)$ indicates that more homogeneous and reacted gels had higher compressive strengths. The microstructures are also consistent with FTIR results, which showed that silicate-activated binders had a higher degree of polymerization. 


\section{Perspectives}

Additional research will be necessary to assess other performance criteria regarding the use of co-fired fly ash as a precursor material. Different types of biomass with additional coal replacement rates than those used in this study will also need to be tested. As a result, these ashes may contain a larger percentage of the secondary fuel ash, and may have different physical or chemical characteristics such as a reduced reactive aluminosilicate content or increased alkali levels. These changes may in turn alter the gel properties in a more discernible way, especially if there is a greater unreactive portion in the co-fired fly ash derived from the biomass combustion. Beneficiation strategies to increase the reactivity of these ashes may be necessary to improve their geopolymerization potential. Still, as demonstrated by this study, certain compositional issues (e.g., high carbon, less vitreous content) can be overcome by tailoring the mix design with particular focus on the activating solutions. Ultimately, the method for developing an optimum mix design will be similar for co-fired fly ash sources as it is currently for coal fly ash sources, and will require characterization and testing to determine the impact of the ash composition on desired binder properties.

\section{Conclusions}

Co-fired fly ashes derived from coal and wood co-combustion were successfully used as precursors for geopolymerization. The coal and co-fired fly ashes used in this study were primarily composed of a vitreous phase intermixed with a small amount of crystalline phases including quartz, mullite and iron oxides. Both co-fired fly ashes had lower aluminosilicate amorphous contents and higher unburned carbon contents compared to the coal fly ash, which was primarily a result of differing combustion processing variables and parent coals, and likely 
not a direct consequence of the use of the secondary biomass fuel. These factors limited the compositional envelope within which these co-fired fly ashes could be alkali-activated to form a hardened gel. Strengths were generally highest for all ashes when using activating solutions with added silica especially with a molar ratio of $\mathrm{Ms}=1$. For the B-CA-4 co-fired fly ash, an increase in the molar concentration of the activator content improved strengths, especially for Naactivation at higher moduli of solution.

Infrared spectra revealed incorporation of $\mathrm{Al}$ and/or substitution of the alkali metal into the gel network after activation of all three ashes. Co-firing appeared to increase the phosphate content of the ash, but this had no discernible impact on gel formation. The shrinkage and expansion features of co-fired fly ash geopolymers upon heating were similar to those observed for the coal fly ash geopolymers. The thermal behavior of these samples was strongly influenced by the free water and gel pore structure, which was primarily controlled by the modulus of solution, the cation type, activation concentration and the ash composition (including the carbon content). The activator type also impacted the microstructure of the co-fired fly ash geopolymers, with Ms $=1$ solutions forming the most homogeneous and densely polymerized gels. These results indicate that co-fired fly ashes can be viably used to form alkali-activated geopolymers, which is a new beneficial end-use for these emerging waste materials.

\section{Acknowledgments}

This research is supported in part by the Department of Energy Office of Science Graduate Fellowship Program (DOE SCGF), made possible in part by the American Recovery and Reinvestment Act of 2009, administered by ORISE-ORAU under contract no. DE-AC0506OR23100. NSF Award Number: 1107736 and the Australian Academy of Science. The 
participation of JLP and SAB in this work was also supported in part by NERC Catalyst Grant

NE/K015680/1. We would like to thank Dr. Nortey Yeboah for providing the SEM image of the A-FA-0 fly ash. We would also like to thank Thomas Dugan, Dr. Laura Gordon, Mitchell Napolitano, Daniella Remolina, Pichet Sahachaiyunta and Suhandy Winata for their help with this research.

\section{References}

[1] Hughes E. Biomass cofiring: economics, policy and opportunities. Biomass Bioenergy 2000;19(6):457-465.

[2] Annual energy outlook 2015. U.S. Energy Information Administration; 2015.

[3] ASTM C618-12a. Standard specification for coal fly ash and raw or calcined natural pozzolan for use in concrete. ASTM International. West Conshohocken; 2012.

[4] EN 450-1:2012. Fly ash for concrete - Part 1: Definition, specifications and conformity criteria. European Committee for Standardization; 2012.

[5] Shearer CR. The productive reuse of coal, biomass and co-fired fly ash. PhD thesis. Atlanta, Georgia Institute of Technology, 2014.

[6] Provis JL, Van Deventer JSJ (Eds.). Alkali activated materials: State-of-the-art report, RILEM TC 224-AAM: Springer/RILEM, Dordrecht; 2014.

[7] Dockter BA, Eylands KE. Development of management options for biomass combustion byproducts. In: Proceedings of the International Ash Utilization Symposium, Lexington, KY; 2003.

[8] Nugteren HW, Butselaar-Orthleib VCL, Izquierdo M. High strength geoolymers produced from coal combustion fly ash. Global NEST J 2009;11(2):155-161. 
[9] Rajamma R, Labrincha JA, Ferreira VM. Alkali activation of biomass fly ash-metakaolin blends. Fuel 2012;98:265-271.

[10] CEN/TR 16443:2013. Backgrounds to the revision of EN 450-1:2005+A1:2007. Fly ash for Concrete. European Committee for Standardization; 2013.

[11] Vassilev SV, Baxter D, Andersen LK, Vassileva CG. An overview of the chemical composition of biomass. Fuel 2010;89(5):913-933.

[12] Rietveld H. A profile refinement method for nuclear and magnetic structures. J Appl Crystallogr 1969;2(2):65-71.

[13] Yeboah NNN, Shearer CR, Burns SE, Kurtis KE. Characterization of biomass and high carbon content coal ash for productive reuse applications. Fuel 2014;116:438-447.

[14] Shearer CR, Kurtis KE. Use of biomass and co-fired fly ash in concrete. ACI Mater J 2015;112(2):209-218.

[15] Saraber AJ. Background to the requirements: Report for discussion for evaluation of the EN 450. Arnhem: KEMA, 2006.

[16] Keyte LM. Fly ash glass chemistry and inorganic polymer cements. In: Provis JL, van Deventer JSJ, editors. Geopolymers: Structure, processing, properties and industrial applications. Cambridge: Woodhead, 2009. p. 15-36.

[17] Chiang H-L, Huang C, Chiang P. The surface characteristics of activated carbon as affected by ozone and alkaline treatment. Chemosphere 2002;47(3):257-265.

[18] Duxson P, Provis JL. Designing precursors for geopolymer cements. J Am Ceram Soc 2008;91(12):3864-3869.

[19] Lee WKW, van Deventer JSJ. Use of infrared spectroscopy to study geopolymerization of heterogeneous amorphous aluminosilicates. Langmuir 2003;19(21):8726-8734. 
[20] Rodriguez ED, Bernal SA, Provis JL, Paya J, Monzo JM, Borrachero MV. Effect of nanosilica-based activators on the performance of an alkali-activated fly ash binder. Cem Concr Compos 2013;35(1):1-11.

[21] Duxson P, Provis JL, Lukey GC, van Deventer JSJ. The role of inorganic polymer technology in the development of 'green concrete'. Cem Concr Res 2007;37(12):1590-1597.

[22] Gadsden JA. Infrared spectra of minerals and related inorganic compounds. London: Butterworths, 1975.

[23] Rahier H, Simons W, van Mele B, Biesemans M. Low-temperature synthesized aluminosilicate glasses: Part 3. Influence of the composition of the silicate solution on production, structure and properties. J Mater Sci 1997;32(9):2237-2247.

[24] Rees CA, Provis JL, Lukey GC, van Deventer JSJ. In situ ATR-FTIR study of the early stages of fly ash geopolymer gel formation. Langmuir 2007;23(17):9076-9082.

[25] Lee WKW, van Deventer JSJ. Structural reorganisation of class F fly ash in alkaline silicate solutions. Colloids Surf A. 2002;211(1):49-66.

[26] Provis JL, Duxson P, Lukey GC, Separovic F, Kriven WM, van Deventer JSJ. Modeling speciation in highly concentrated alkaline silicate solutions. Ind Eng Chem Res 2005;44(23):8899-8908.

[27] Criado M, Fernández-Jiménez A, Palomo A. Alkali activation of fly ash: Effect of the $\mathrm{SiO}_{2} / \mathrm{Na}_{2} \mathrm{O}$ ratio Part I: FTIR study. Microporous Mesoporous Mater 2007;106(1-3):180191.

[28] McCormick AV, Bell AT. The solution chemistry of zeolite precursors. Catal Rev Sci Eng. 1989;31(1-2):97-127.

[29] Vogel W. Structure and crystallization of glasses. New York: Pergomon Press, 1971. 
[30] Vassilev SV, Baxter D, Vassileva CG. An overview of the behaviour of biomass during combustion: Part I. Phase-mineral transformations of organic and inorganic matter. Fuel 2013;112:391-449.

[31] Provis JL, Bernal SA. Geopolymers and related alkali-activated materials. Annu Rev Mater Res 2014;44(1):299-327.

[32] Provis JL, Rose V, Bernal SA, van Deventer JSJ. High-resolution nanoprobe X-ray fluorescence characterization of heterogeneous calcium and heavy metal distributions in alkali-activated fly ash. Langmuir 2009;25(19):11897-11904.

[33] Misra MK, Ragland KW, Baker AJ. Wood ash composition as a function of furnace temperature. Biomass Bioenergy 1993;4(2):103-116.

[34] Gao YM, Kulaots G, Chen X, Suuberg EM, Hurt RH, Veranth JM. The effect of solid fuel type and combustion conditions on residual carbon properties and fly ash quality. Proc Combus Inst 2002;29:475-483.

[35] Duxson P, Lukey GC, van Deventer JSJ. Physical evolution of Na-geopolymer derived from metakaolin up to $1000{ }^{\circ} \mathrm{C}$. J Mater Sci 2007;42(9):3044-3054.

[36] Paya J, Monzo J, Borrachero MV, Amahjour F, Peris-Mora E. Loss on ignition and carbon content in pulverized fuel ashes (PFA): Two crucial parameters for quality control. J Chem Technol Biotechnol 2002;77(3):251-255.

[37] Provis JL, Yong CZ, Duxson P, van Deventer JSJ. Correlating mechanical and thermal properties of sodium silicate-fly ash geopolymers. Colloids Surf A 2009;336(1-3):57-63.

[38] Rickard WDA, van Riessen A, Walls P. Thermal character of geopolymers synthesized from Class F fly ash containing high concentrations of iron and $\alpha$-quartz. Int J Appl Ceram Technol 2010;7(1):81-88. 
[39] Provis JL, Harrex RM, Bernal SA, Duxson P, van Deventer JSJ. Dilatometry of geopolymers as a means of selecting desirable fly ash sources. J Non-Cryst Solids 2012;358(16):1930-1937.

[40] Rickard WDA, Temuujin J, van Riessen A. Thermal analysis of geopolymer pastes synthesised from five fly ashes of variable composition. J Non-Cryst Solids 2012;358(15):1830-1839.

[41] Rahier H, van Mele B, Wastiels J. Low-temperature synthesized aluminosilicate glasses: Part 2. Rheological transformations during low-temperature cure and high-temperature properties of a model compound. J Mater Sci 1996;31(1):80-85.

[42] Duxson P, Lukey GC, Separovic F, van Deventer JSJ. Effect of alkali cations on aluminum incorporation in geopolymeric gels. Ind Eng Chem Res 2005;44(4):832-839.

[43] Duxson P, Lukey GC, van Deventer JSJ. The thermal evolution of metakaolin geopolymers: Part 2. Phase stability and structural development. J Non-Cryst Solids 2007;353(2223):2186-2200.

[44] Duxson P, Lukey GC, van Deventer JSJ. Evolution of gel structure during thermal processing of Na-geopolymer gels. Langmuir 2006;22(21):8750-8757.

[45] Lubansky AS, Yeow YL, Leong YK, Wickramasinghe SR, Han BB. A general method of computing the derivative of experimental data. AIChE J 2006;52(1):323-332.

[46] Provis JL, Kilcullen A, Duxson P, Brice DG, van Deventer JSJ. Stabilization of lowmodulus sodium silicate solutions by alkali substitution. Ind Eng Chem Res 2012;51(5):2483-2486.

[47] Lloyd RR, Provis JL, van Deventer JSJ. Microscopy and microanalysis of inorganic polymer cements. 2: The gel binder. J Mater Sci 2009;44(2):620-631. 


\section{Figure Captions}

Figure 1: Fly ash particle size distributions.

Figure 2: Compressive strength results obtained using (a) sodium and (b) potassium activating solutions. The $7 \%$ and $10 \%$ values indicate the activator dose of $\mathrm{Na}_{2} \mathrm{O}$ or $\mathrm{Na}_{2} \mathrm{O}_{\text {eq }}$ by mass of ash. C-CA-15 did not form a hardened geopolymer gel at $\mathrm{Ms}=0$ or 2 and is plotted at zero strength.

Figure 3: Fourier transform infrared spectra of alkali-activated (a) A-FA-0, (b) $7 \% \mathrm{Na}_{2} \mathrm{O}_{\text {eq }} \mathrm{B}$ CA-4, (c) $10 \% \mathrm{Na}_{2} \mathrm{O}_{\text {eq }}$ B-CA-4 and (d) C-CA-15 cured for 7 days. The bottom spectrum in each plot represents the raw ash, and each spectrum is marked according to the cation and Ms value in the activator.

Figure 4: The main asymmetric Si-O-T stretching band locations after 28 days of curing for ashes alkali-activated with (a) sodium and (b) potassium solutions. The $7 \%$ and $10 \%$ values indicate the activator dose of $\mathrm{Na}_{2} \mathrm{O}$ or $\mathrm{Na}_{2} \mathrm{O}_{\text {eq }}$ by mass of ash.

Figure 5: X-ray diffraction patterns of Na-activated pastes for (a) A-FA-0 (b) $7 \% \mathrm{Na}_{2} \mathrm{O}$ B-CA-4, (c) $10 \% \mathrm{Na}_{2} \mathrm{O}$ B-CA-4 and (d) C-CA-15. $\mathrm{M}$ is mullite, Q is quartz, $\mathrm{F}$ is a combination of iron oxides, $\mathrm{H}$ is hydrosodalite, $\mathrm{N}$ is a hydrous sodium silicate, $\mathrm{J}$ is faujasite, $\mathrm{C}$ is chabazite- $\mathrm{Na}$, $\mathrm{A}$ is analcime and $\mathrm{T}$ is natron.

Figure 6: Thermogravimetric determination of weight loss of raw and alkali-activated (a) A-FA0, (b) $7 \% \mathrm{Na}_{2} \mathrm{O}_{\text {eq }}$ B-CA-4, (c) $10 \% \mathrm{Na}_{2} \mathrm{O}_{\text {eq }}$ B-CA-4 and (d) C-CA-15.

Figure 7: Dilatometry curves for alkali-activated (a) A-FA-0, (b) $7 \% \mathrm{Na}_{2} \mathrm{O}_{\text {eq }}$ B-CA-4, (c) $10 \%$ $\mathrm{Na}_{2} \mathrm{O}_{\text {eq }}$ B-CA-4 and (d) C-CA-15.

Figure 8: The first derivative (dashed line, left axis) and second derivative (solid line, right axis) of the A-FA-0 Na-1-7 dilatometric curve. The expansion peak at $740^{\circ} \mathrm{C}$ is circled.

Figure 9: Relationship between the onset temperature of the high-silica gel expansion peak and compressive strengths of (a) sodium-activated and (b) potassium-activated geopolymer mortars.

Figure 10: SEM images of (a) A-FA-0, (b) B-CA-4 and (c) C-CA-15 ashes.

Figure 11: SEM images of B-CA-4 pastes activated by: (a) Na-0-10, (b) Na-1-10 and (c) Na-210.

Figure 12: SEM images of B-CA-4 pastes activated by: (a) K-0-10, (b) K-1-10 and (c) K-2-10. 


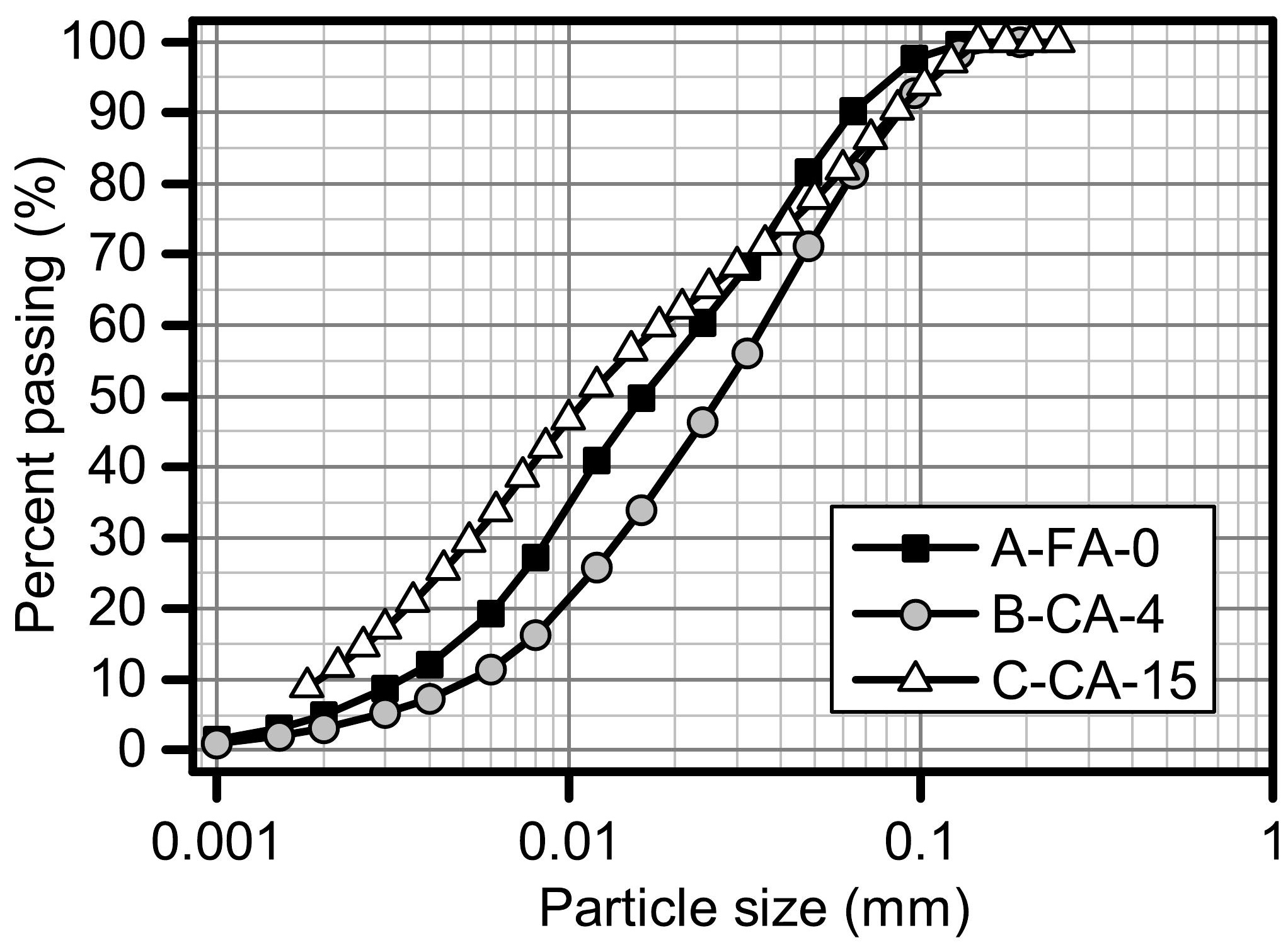




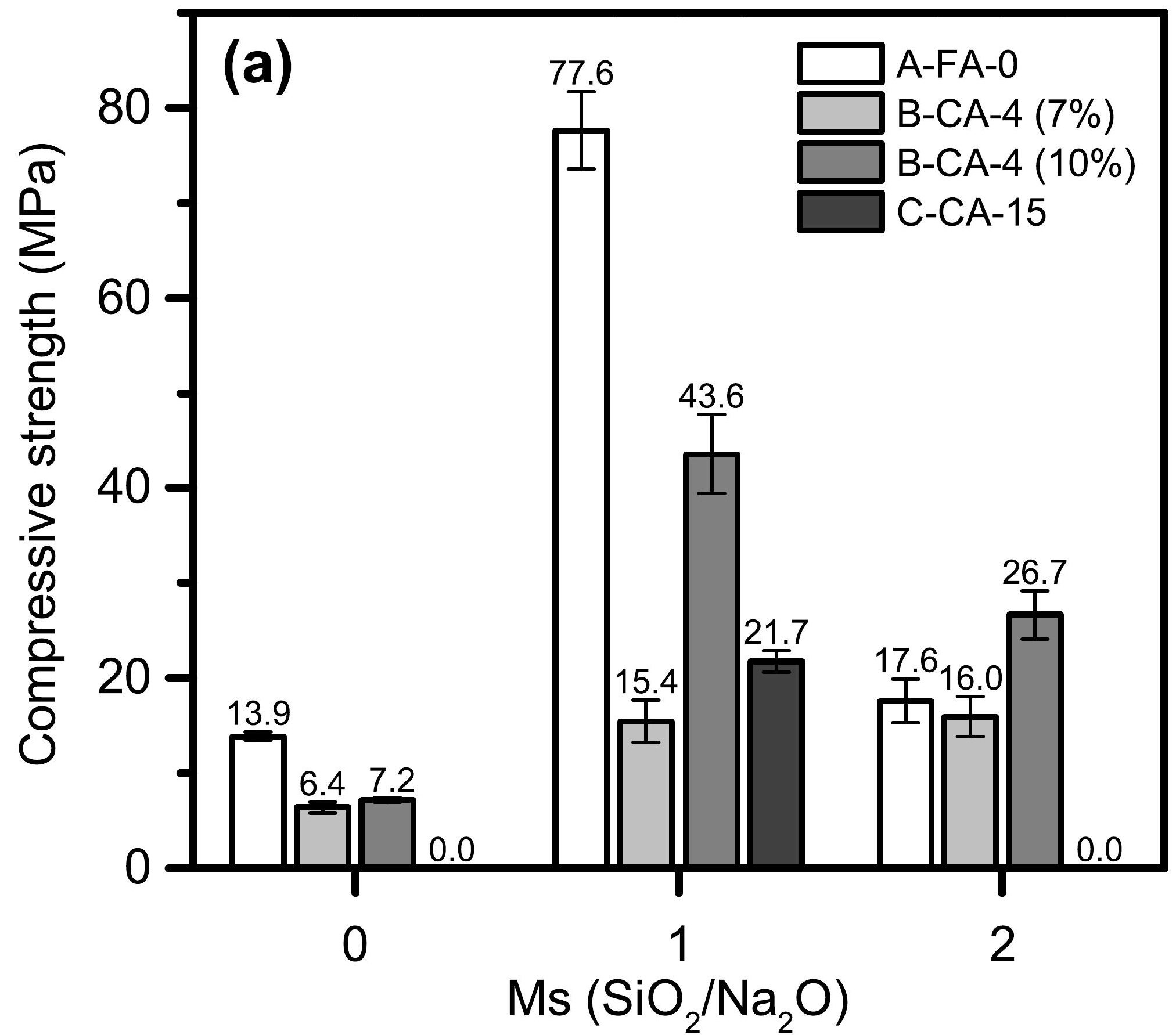




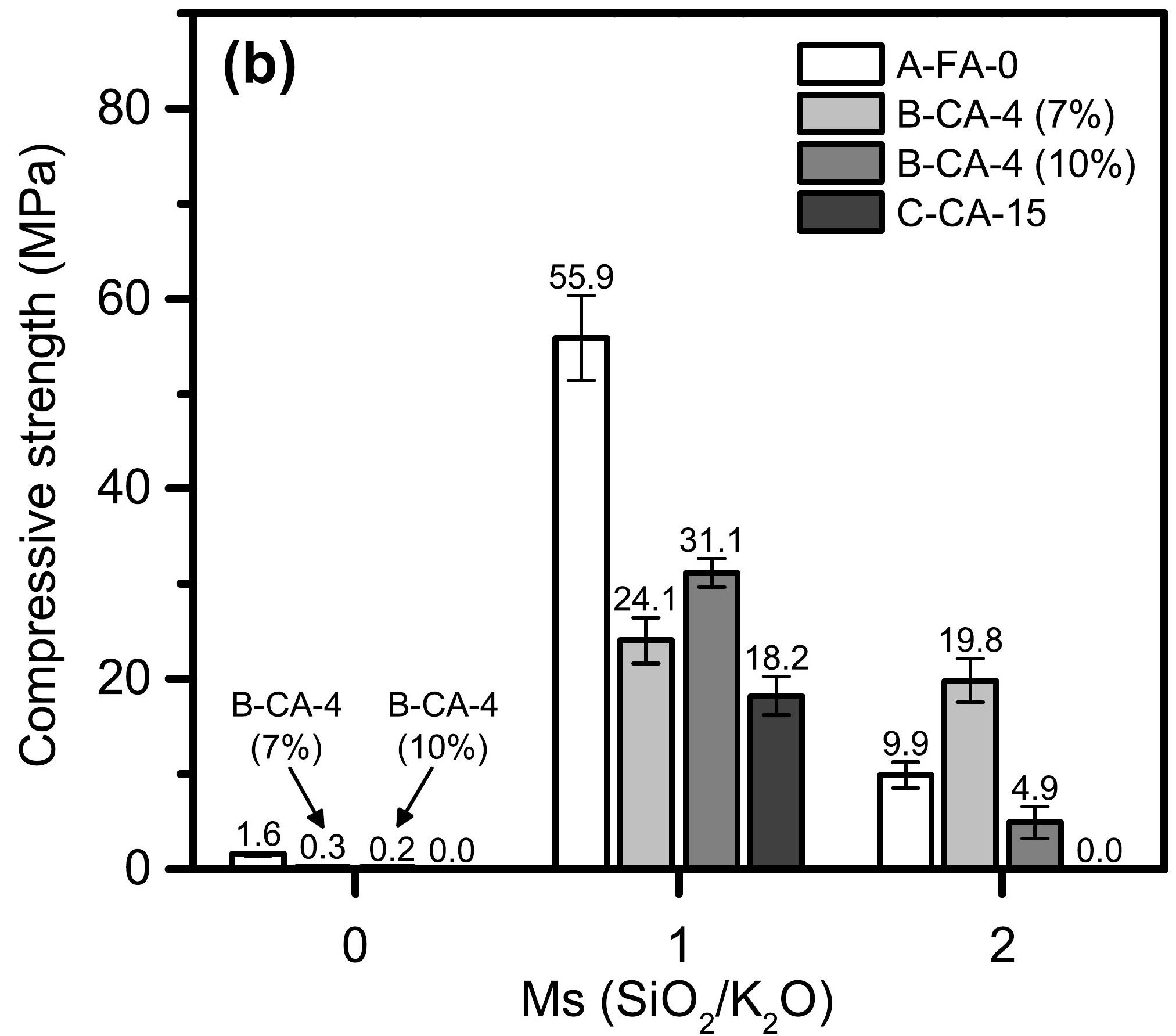


Figure $3 a$

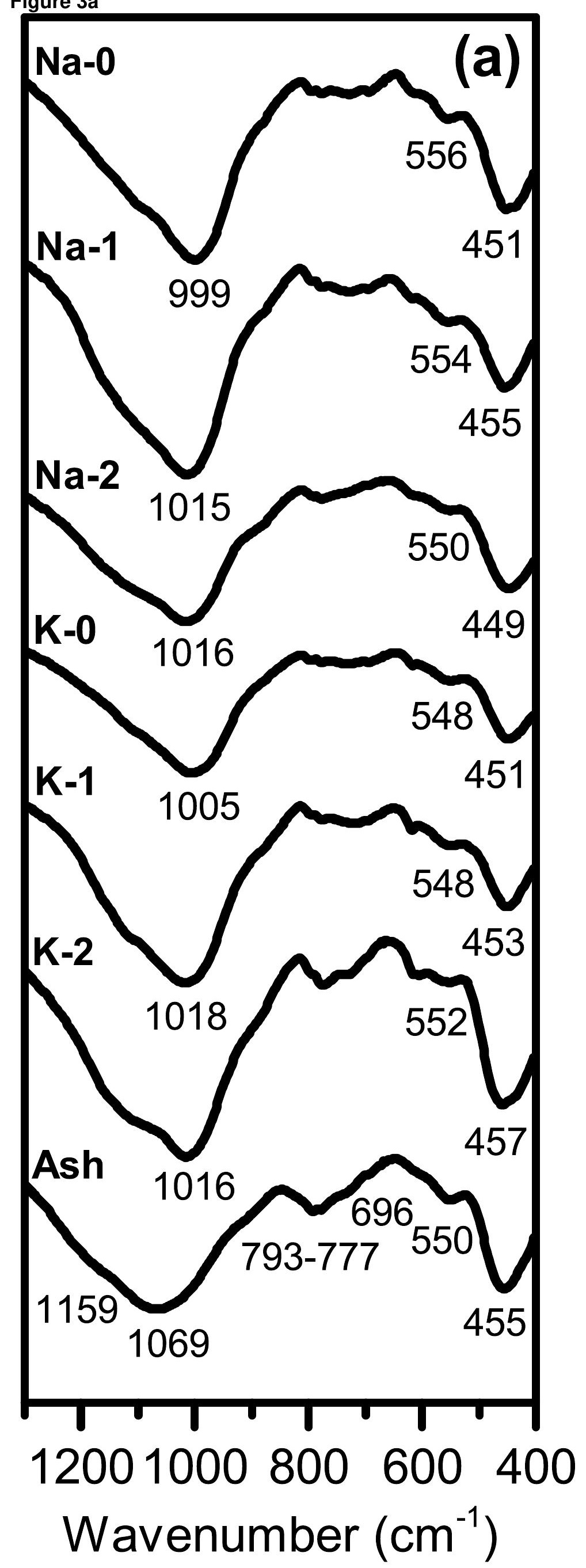


Figure 3c

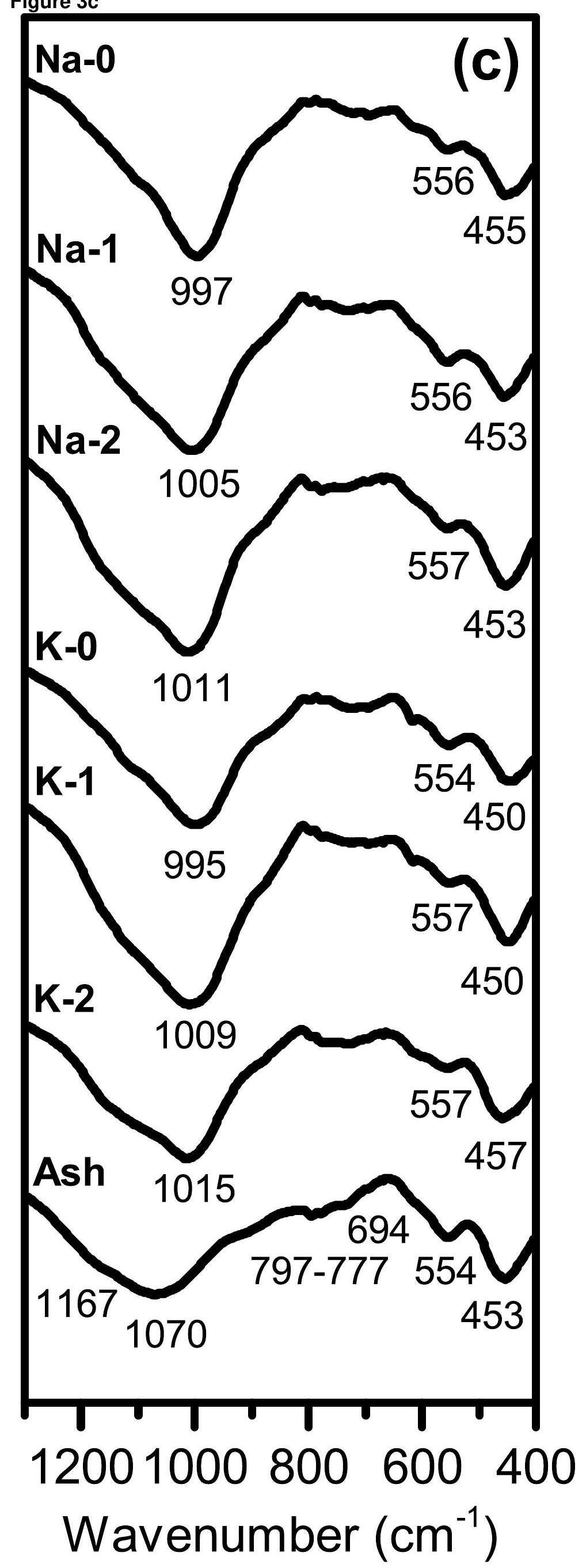




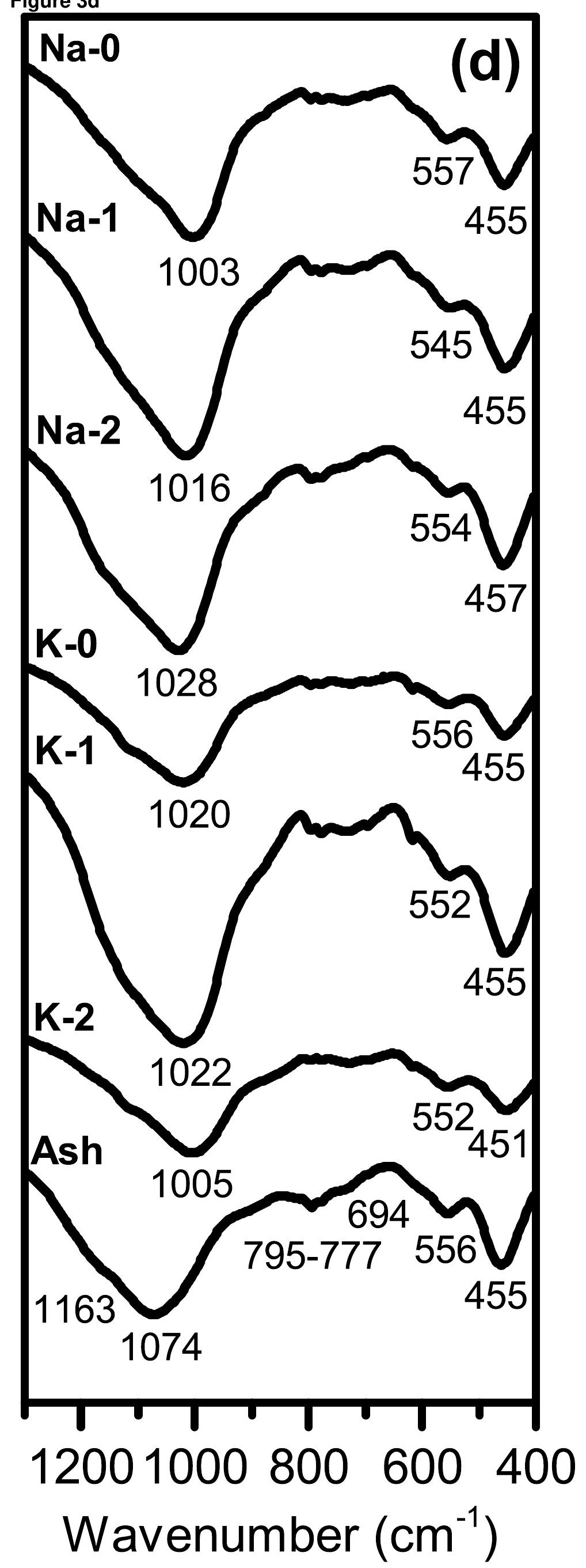




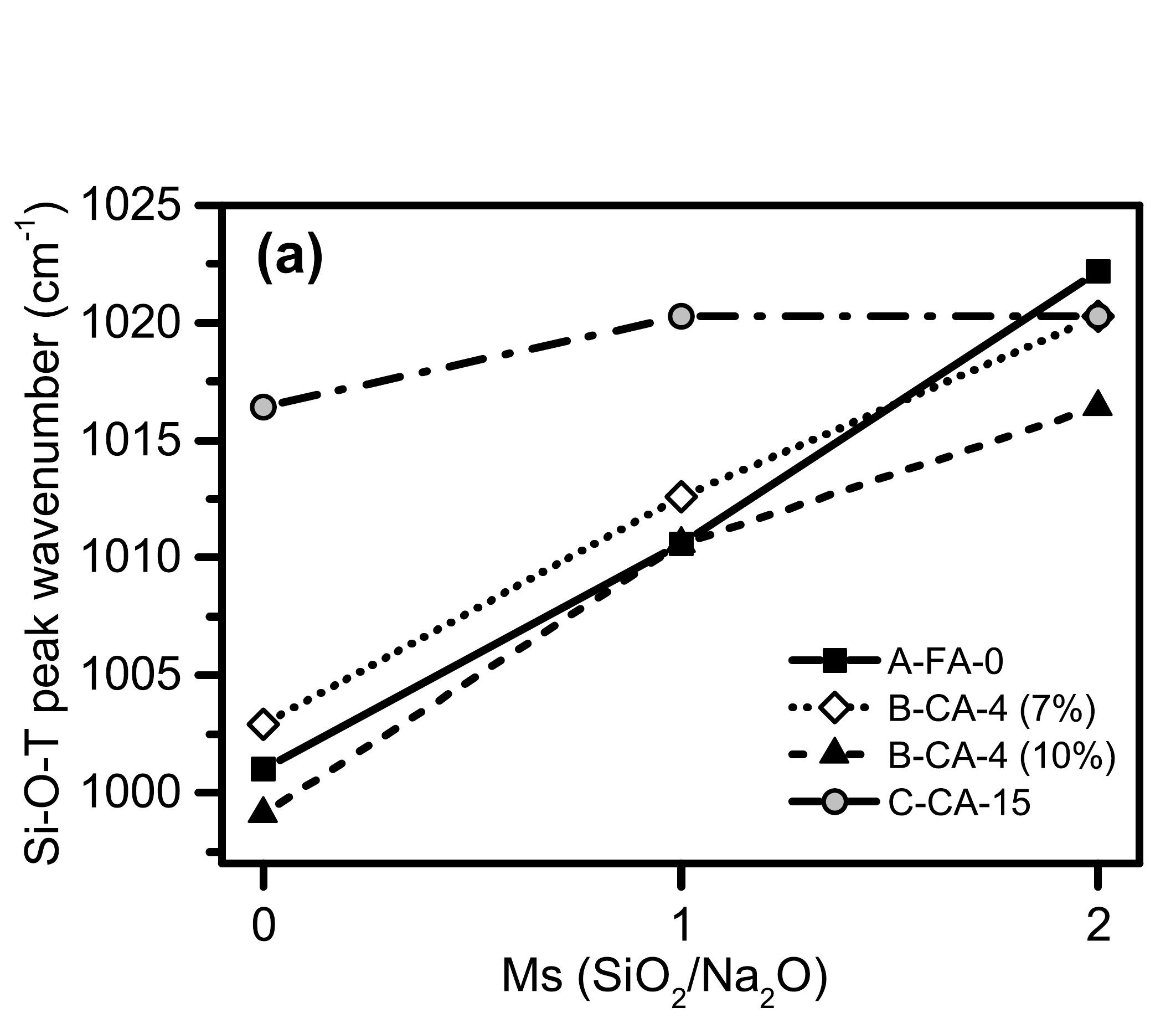

Figure $4 a$

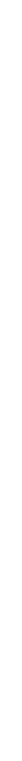

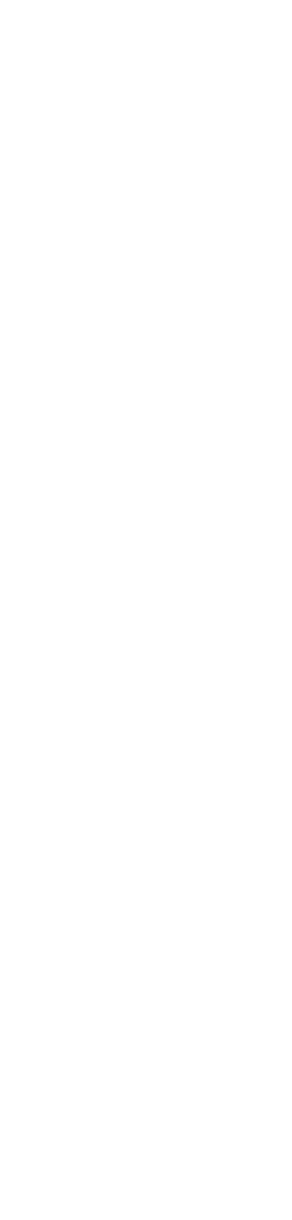




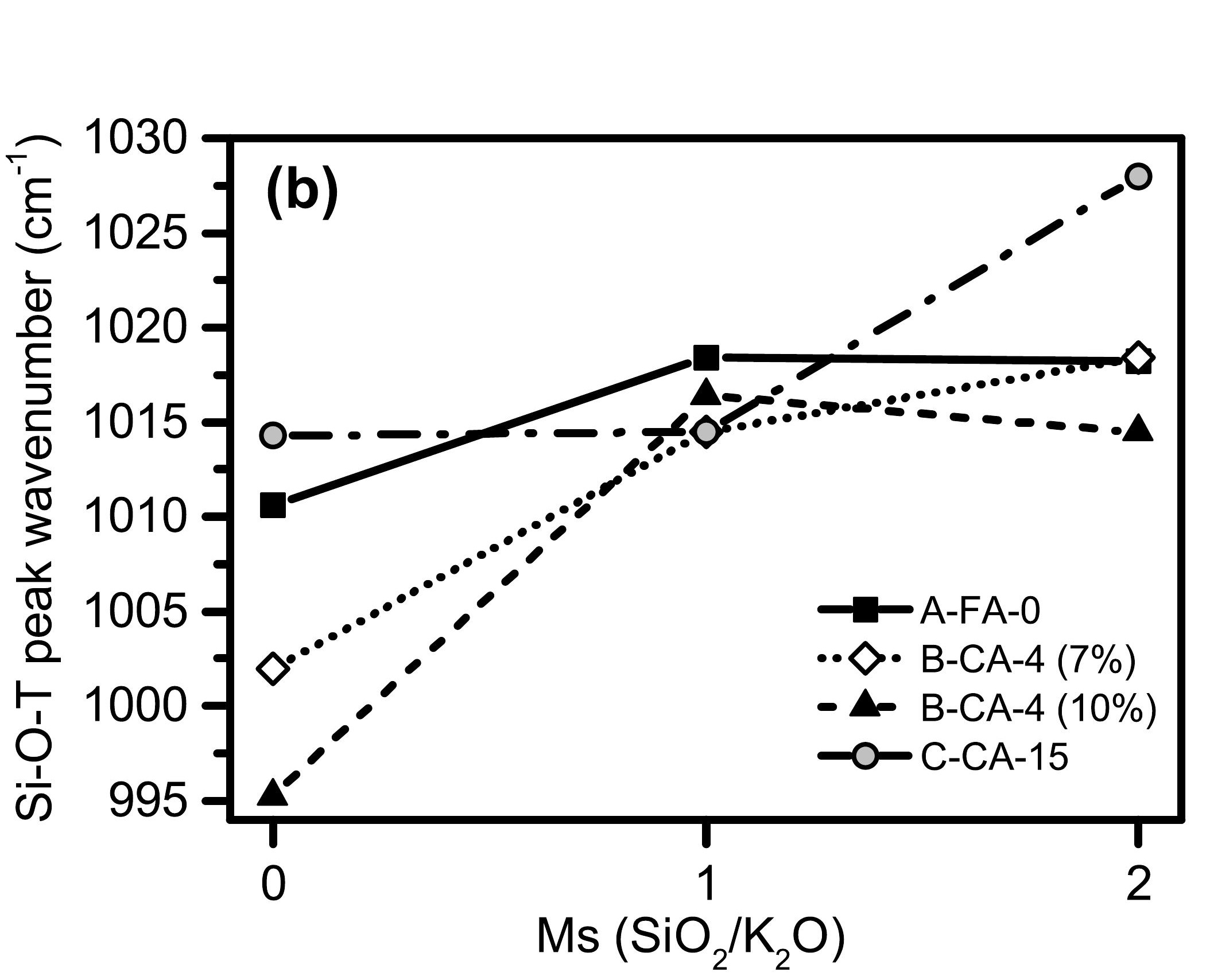

Figure 4b

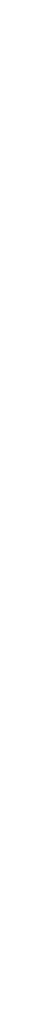




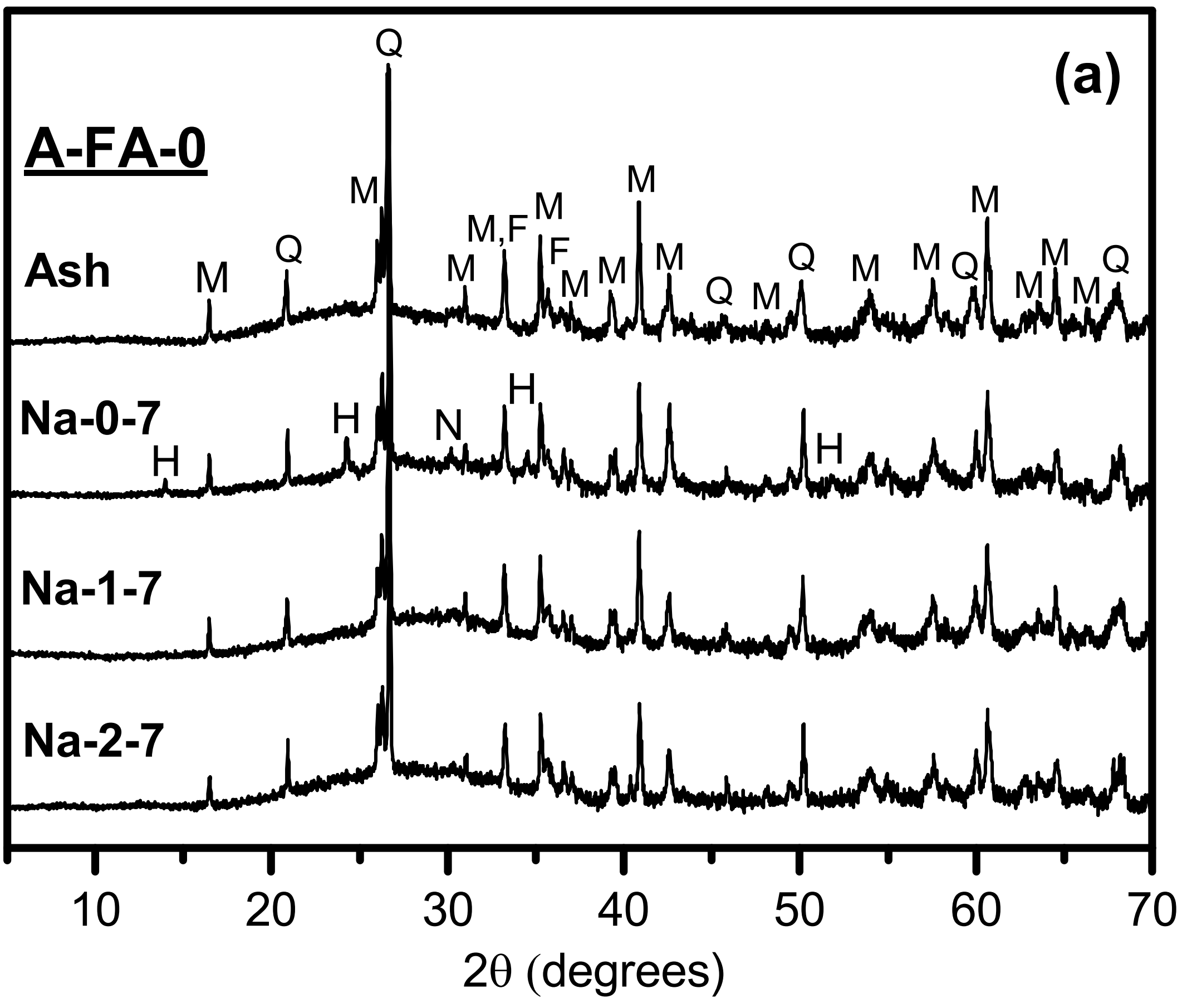




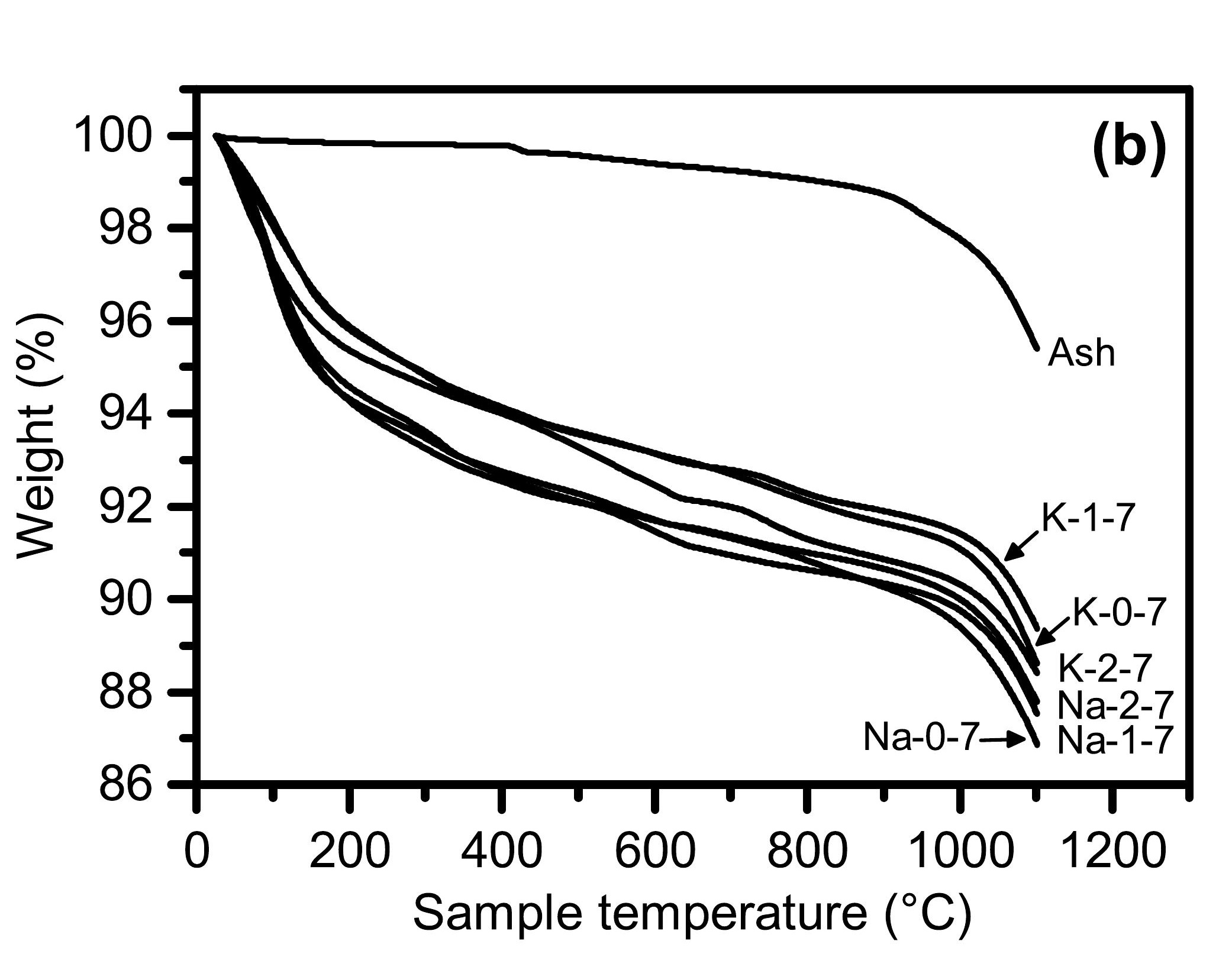

Figure $6 b$

Figure $6 \mathrm{~b}$

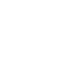

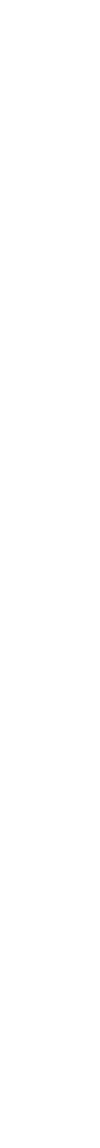

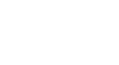

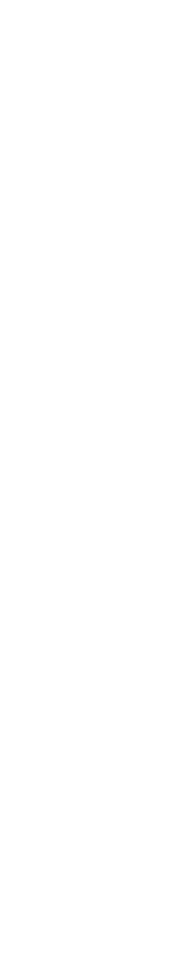

.

.

政
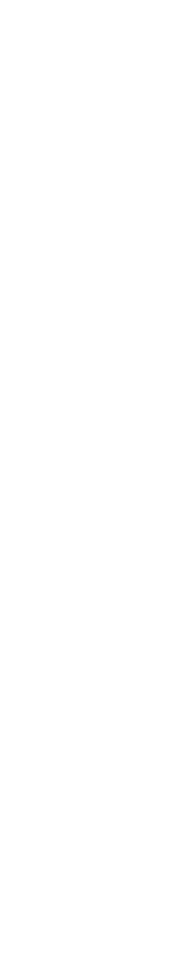

.

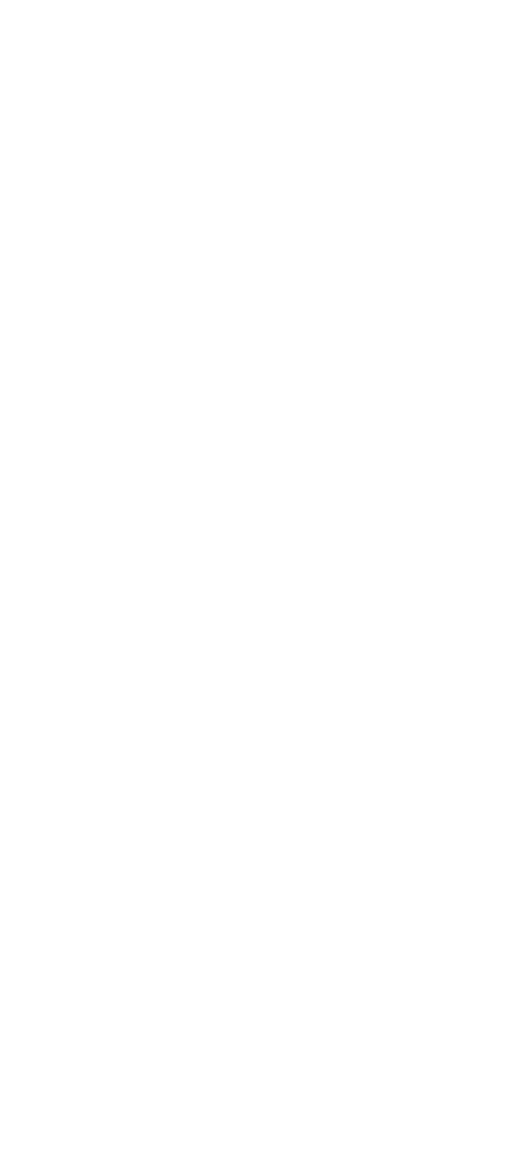




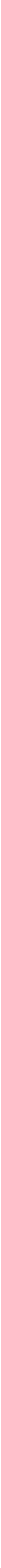

Figure 7c
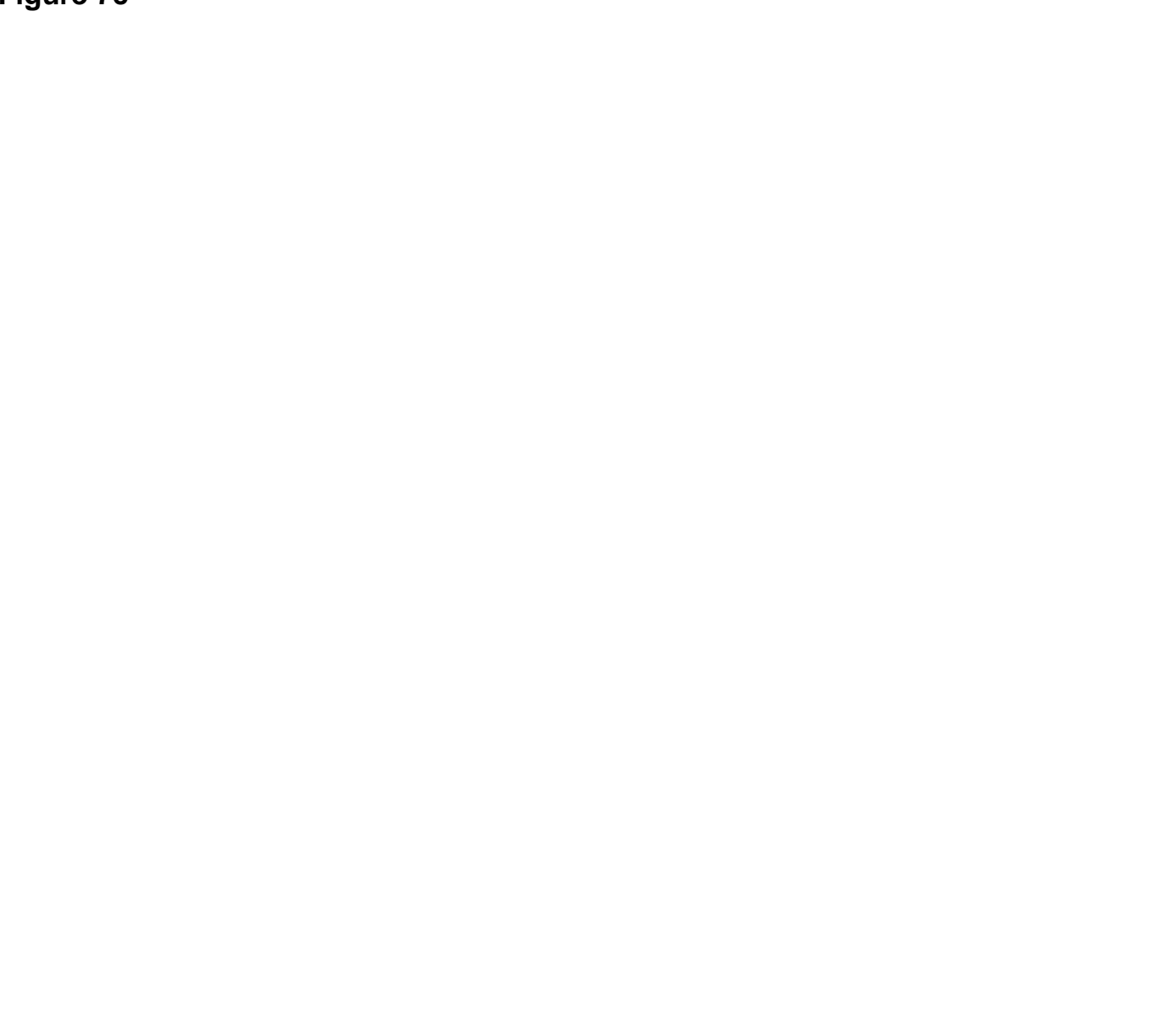


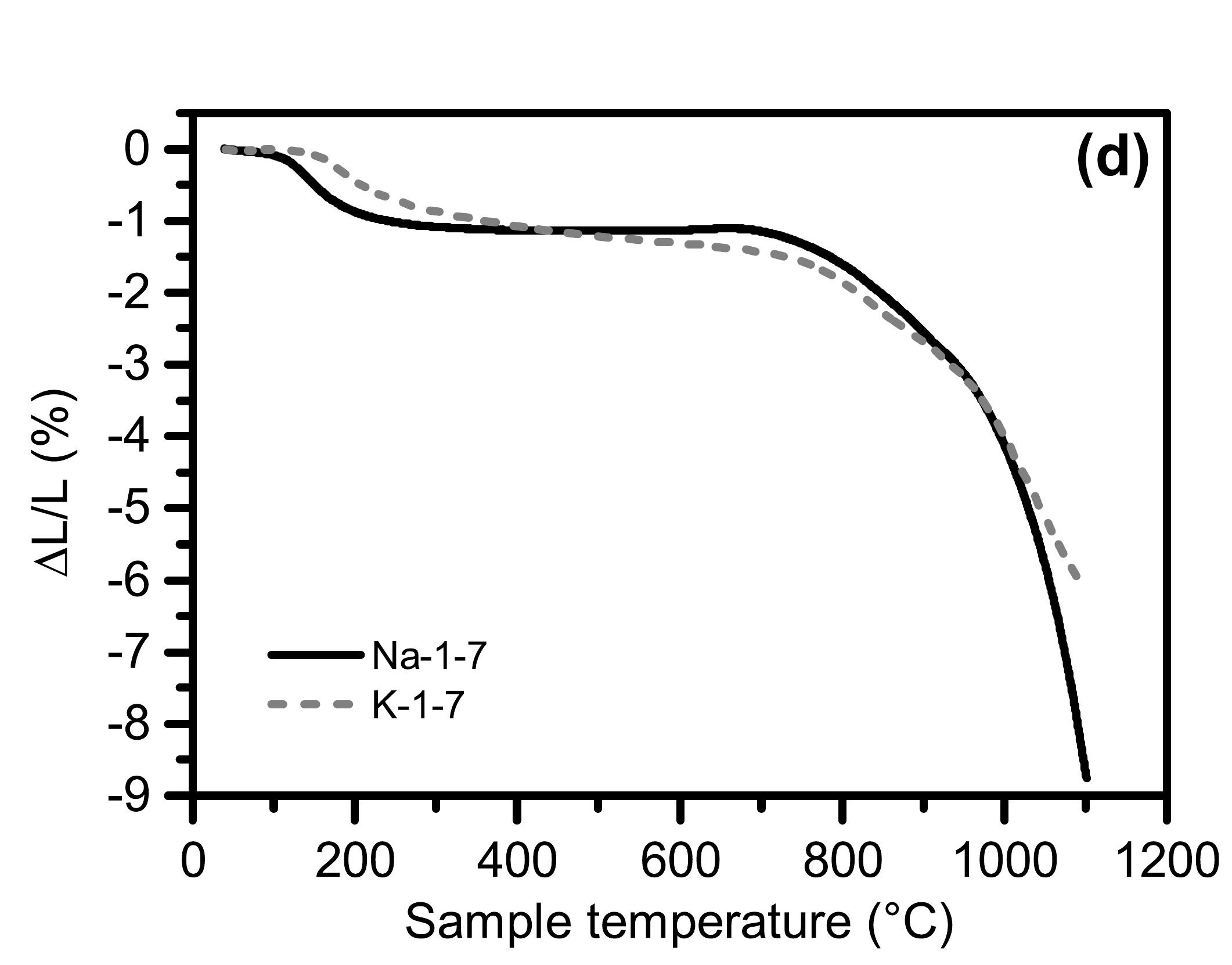

Figure $7 d$
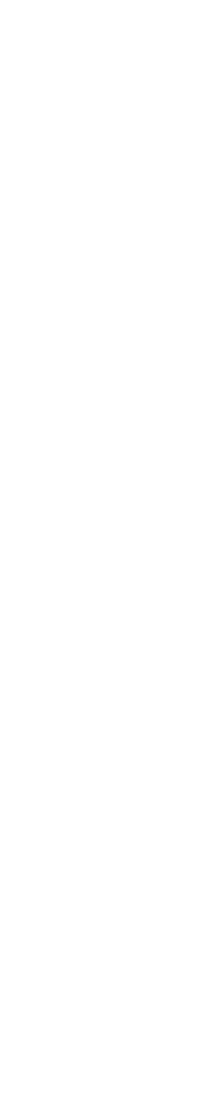

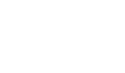

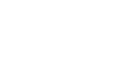

.

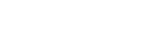

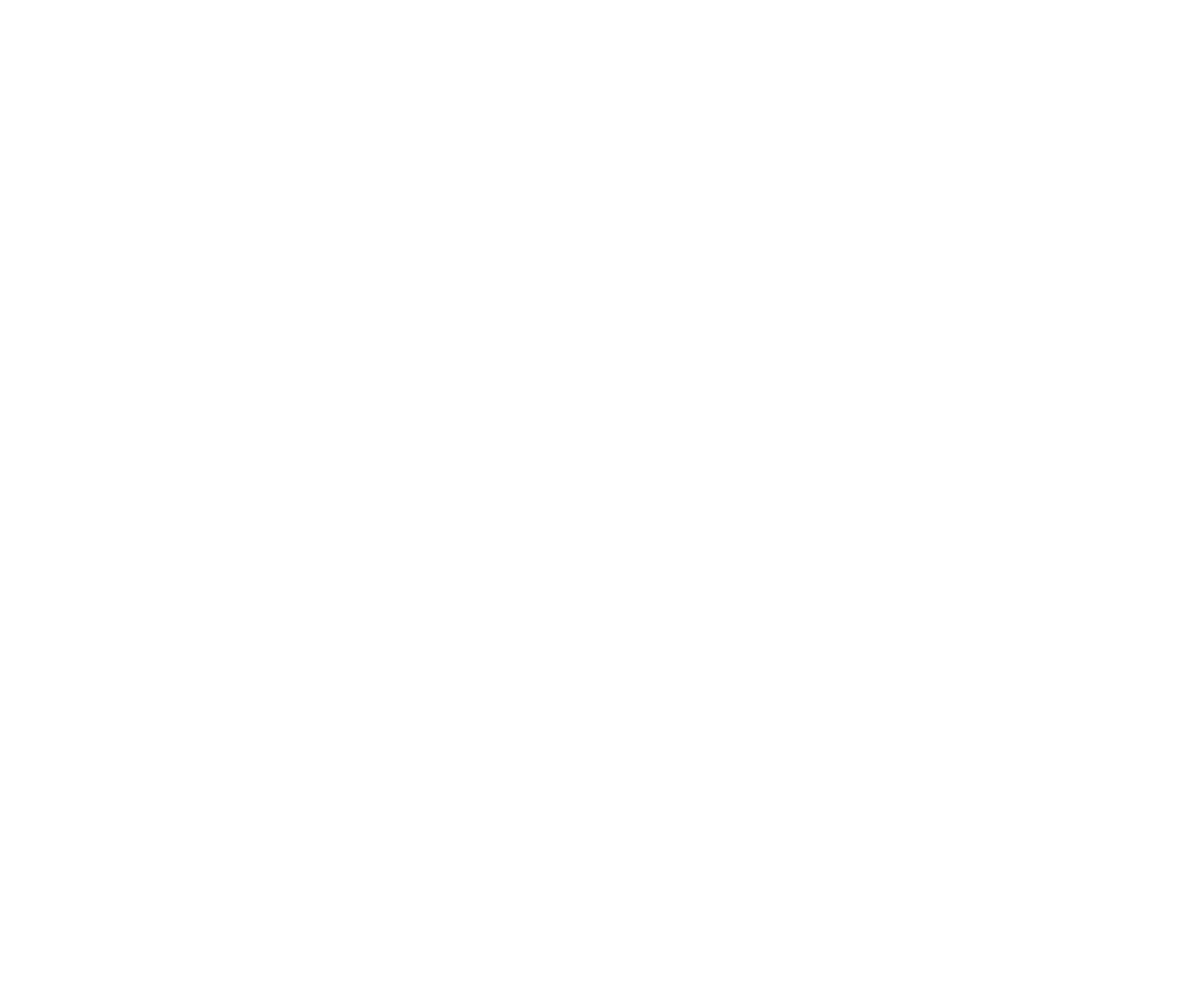


Figure 8

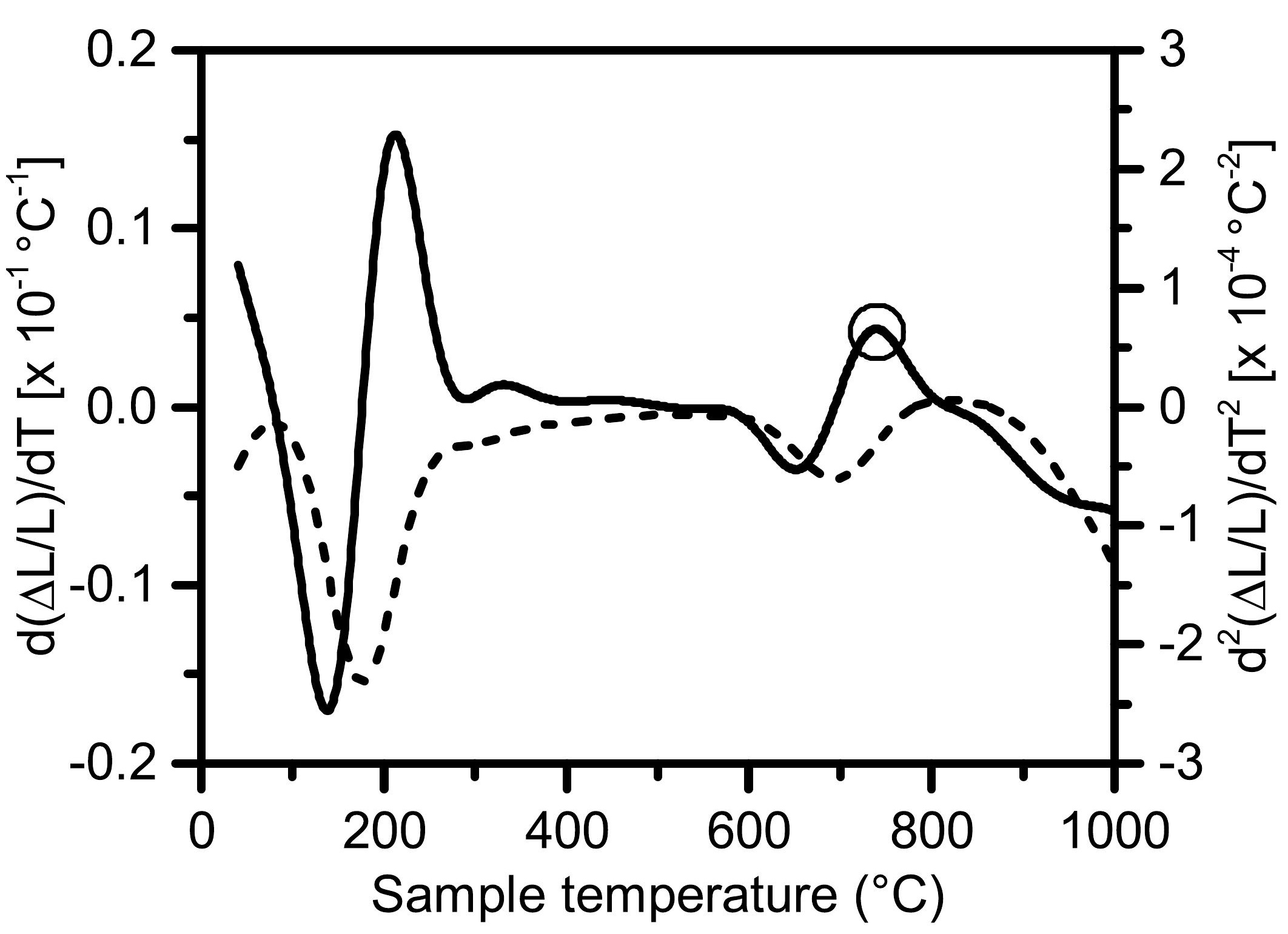




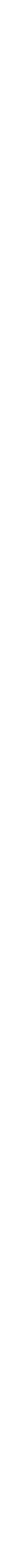

Figure 9a 


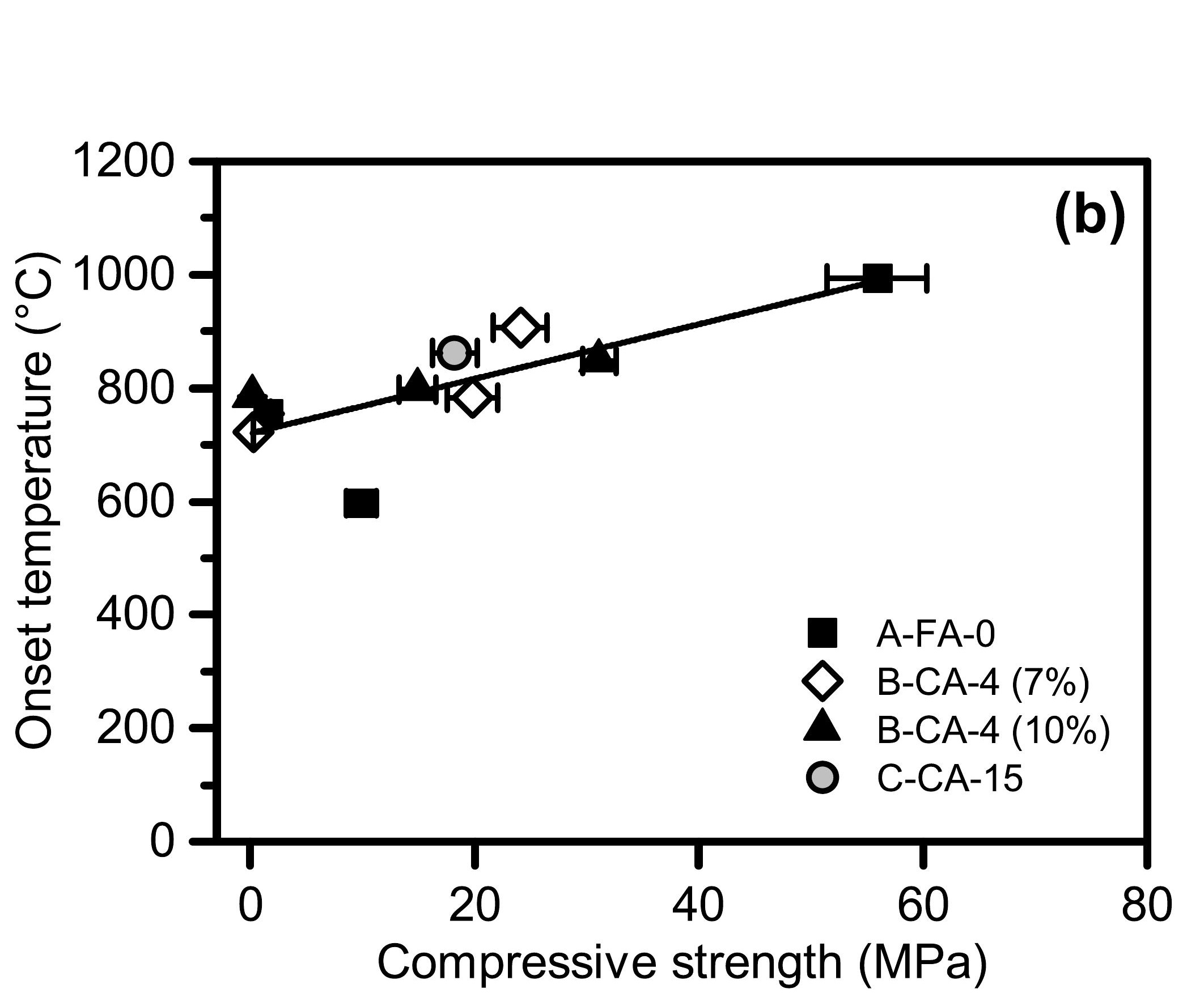

Figure $9 b$ 


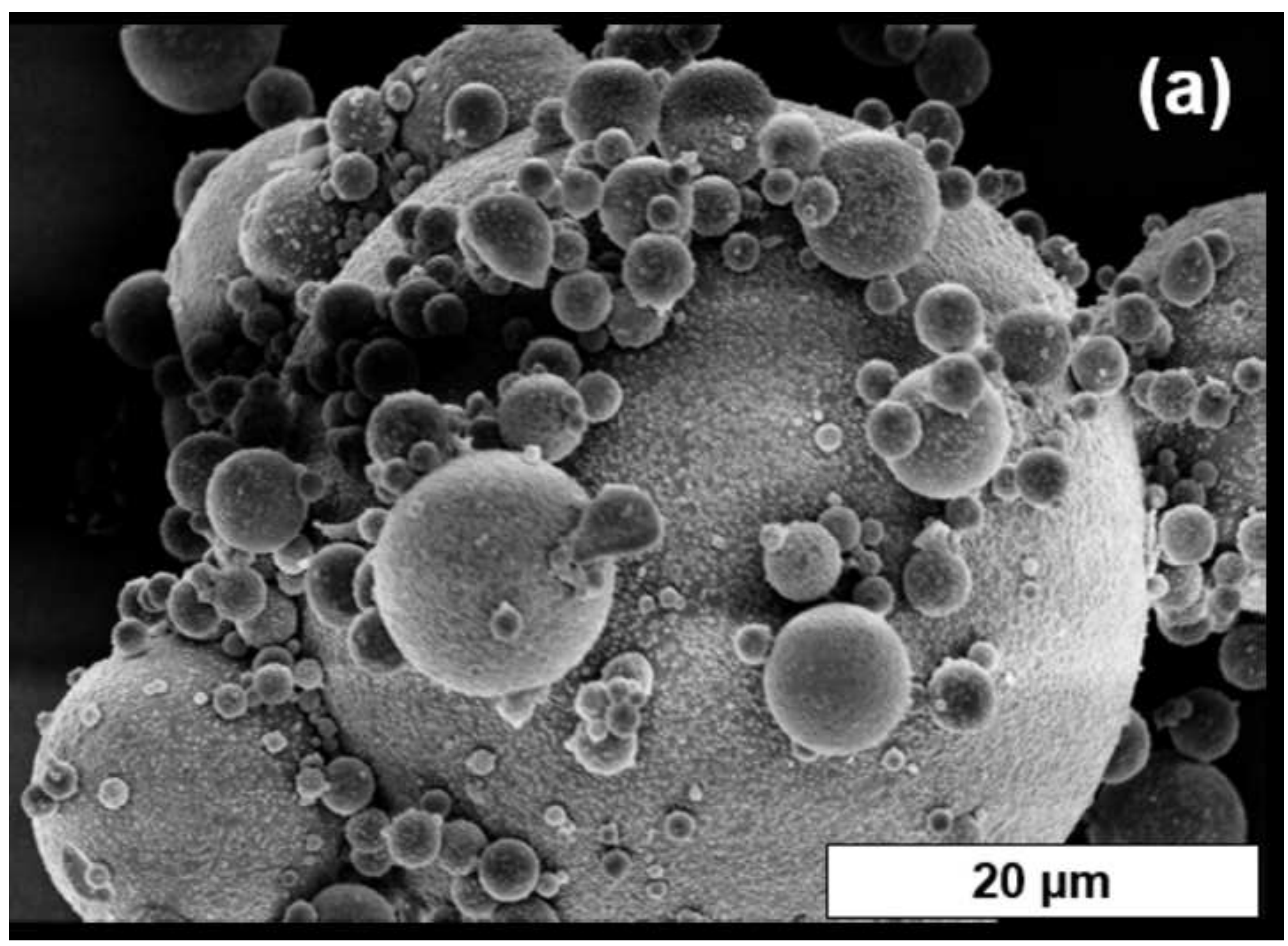




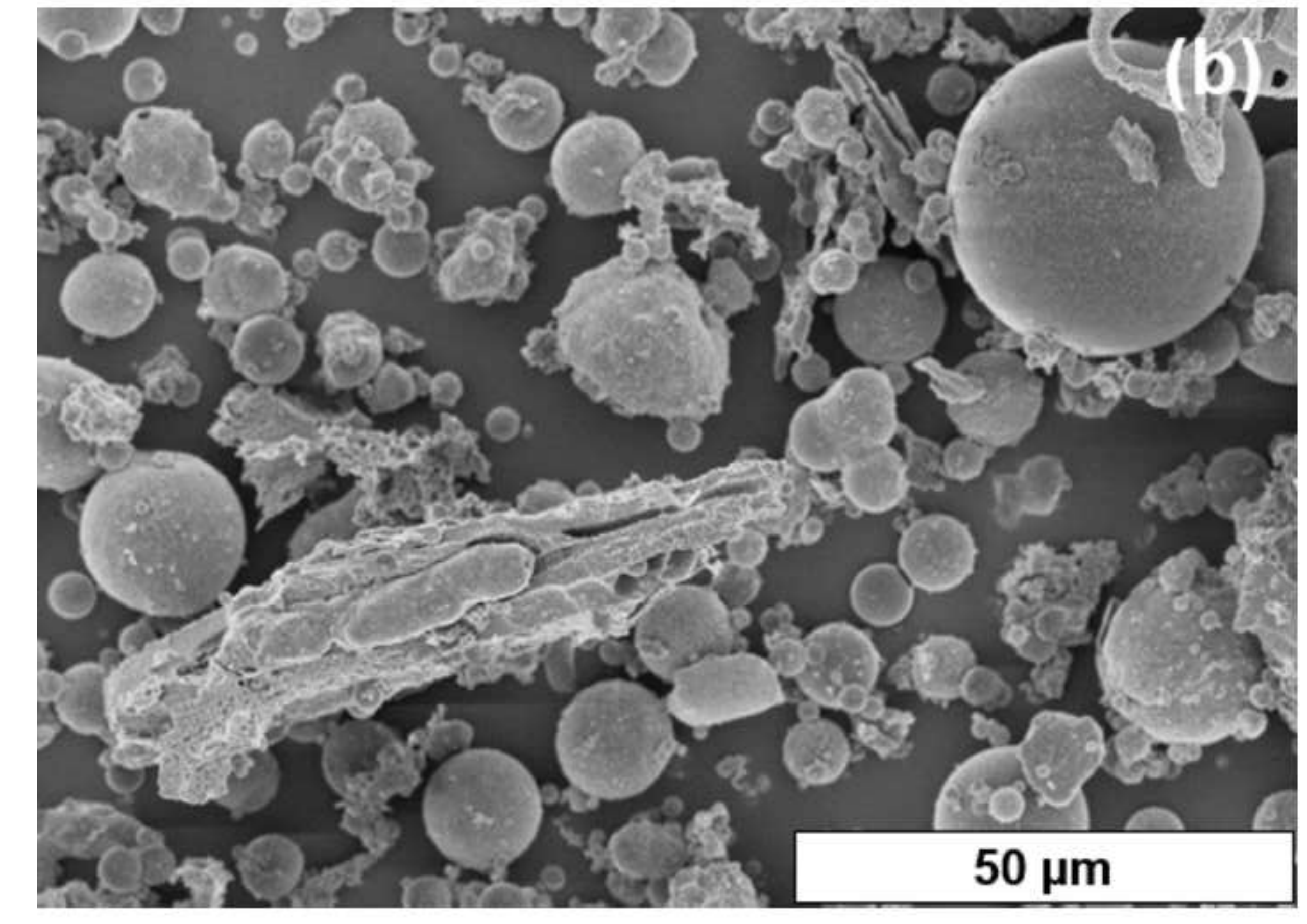

.
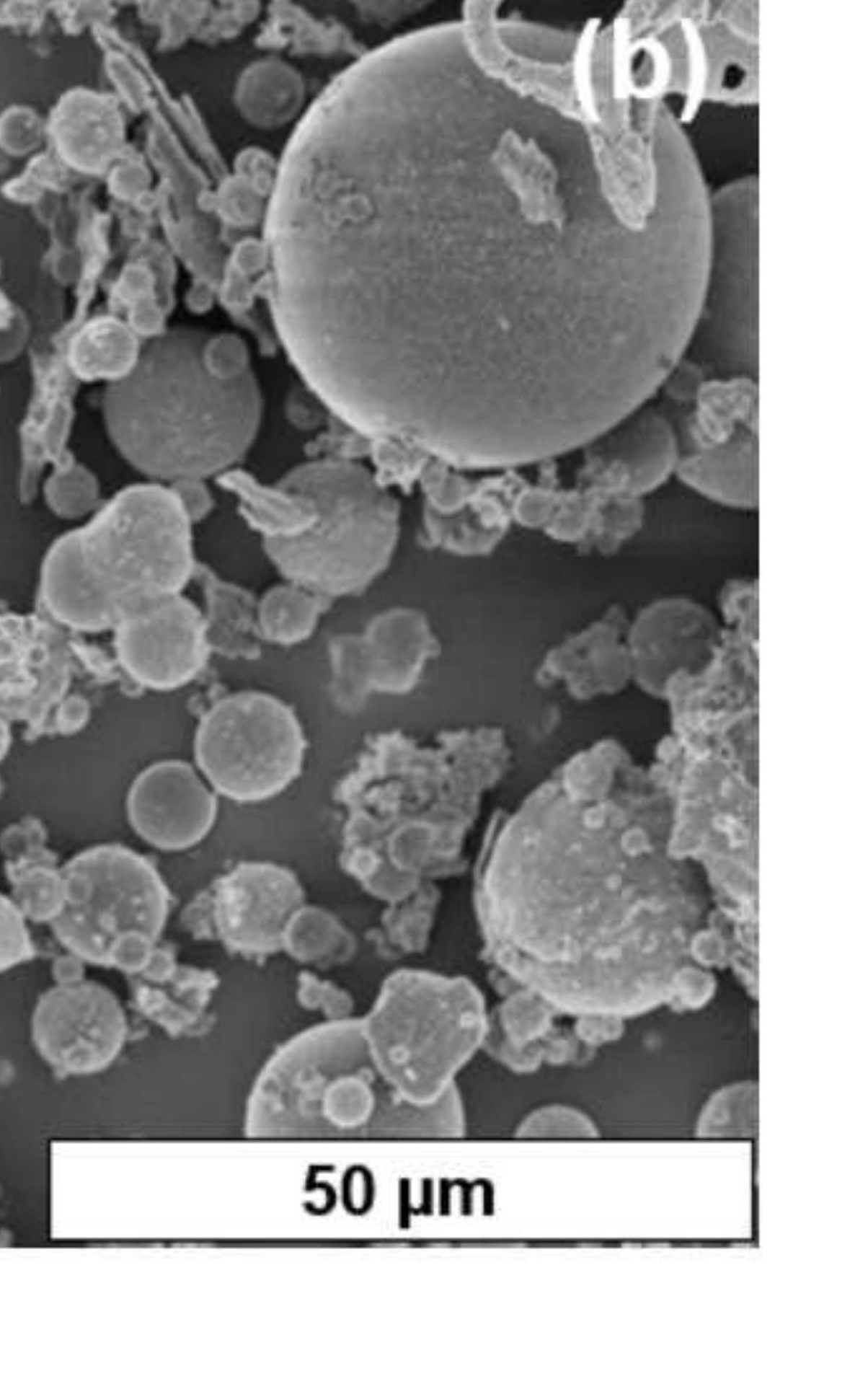


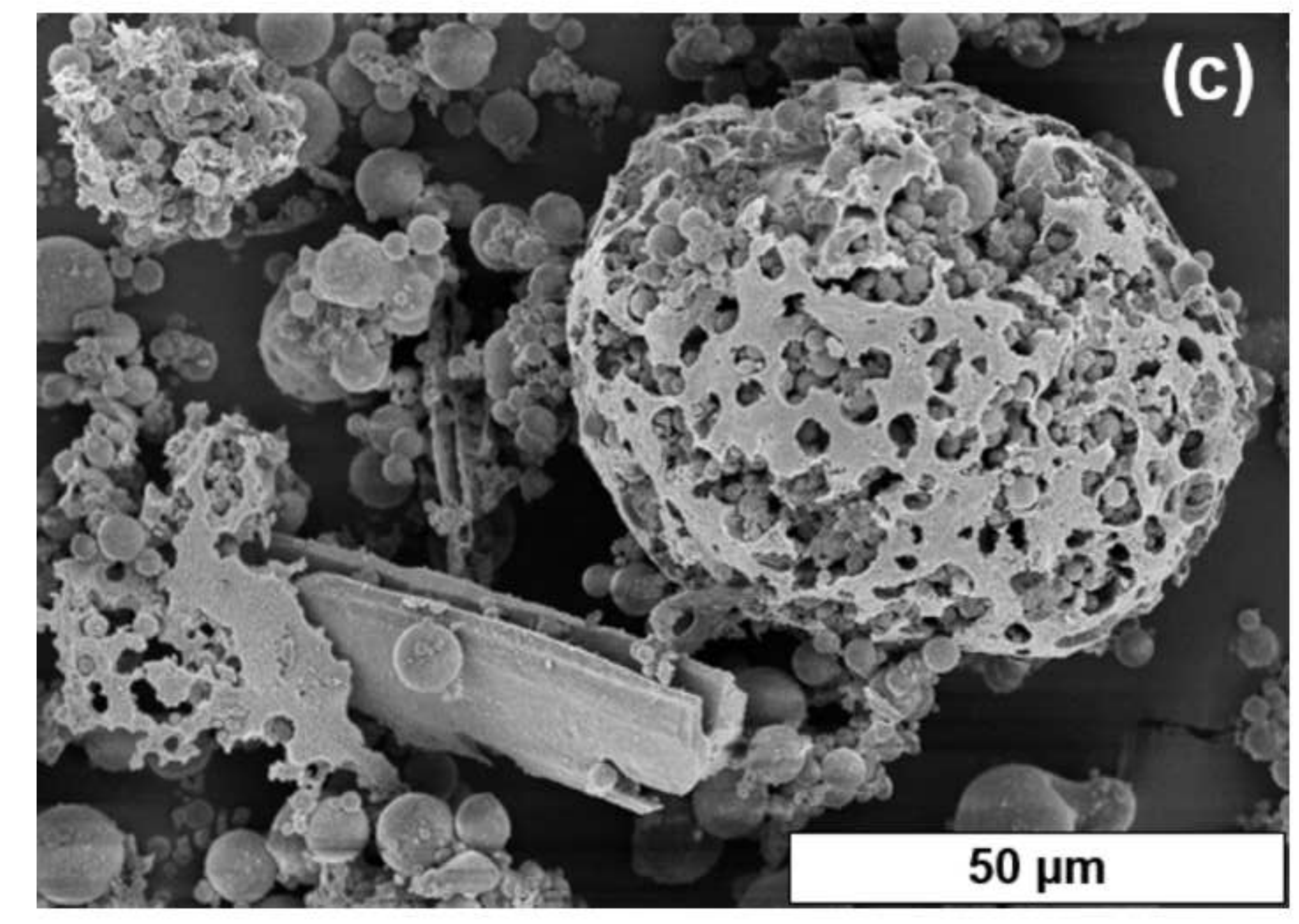




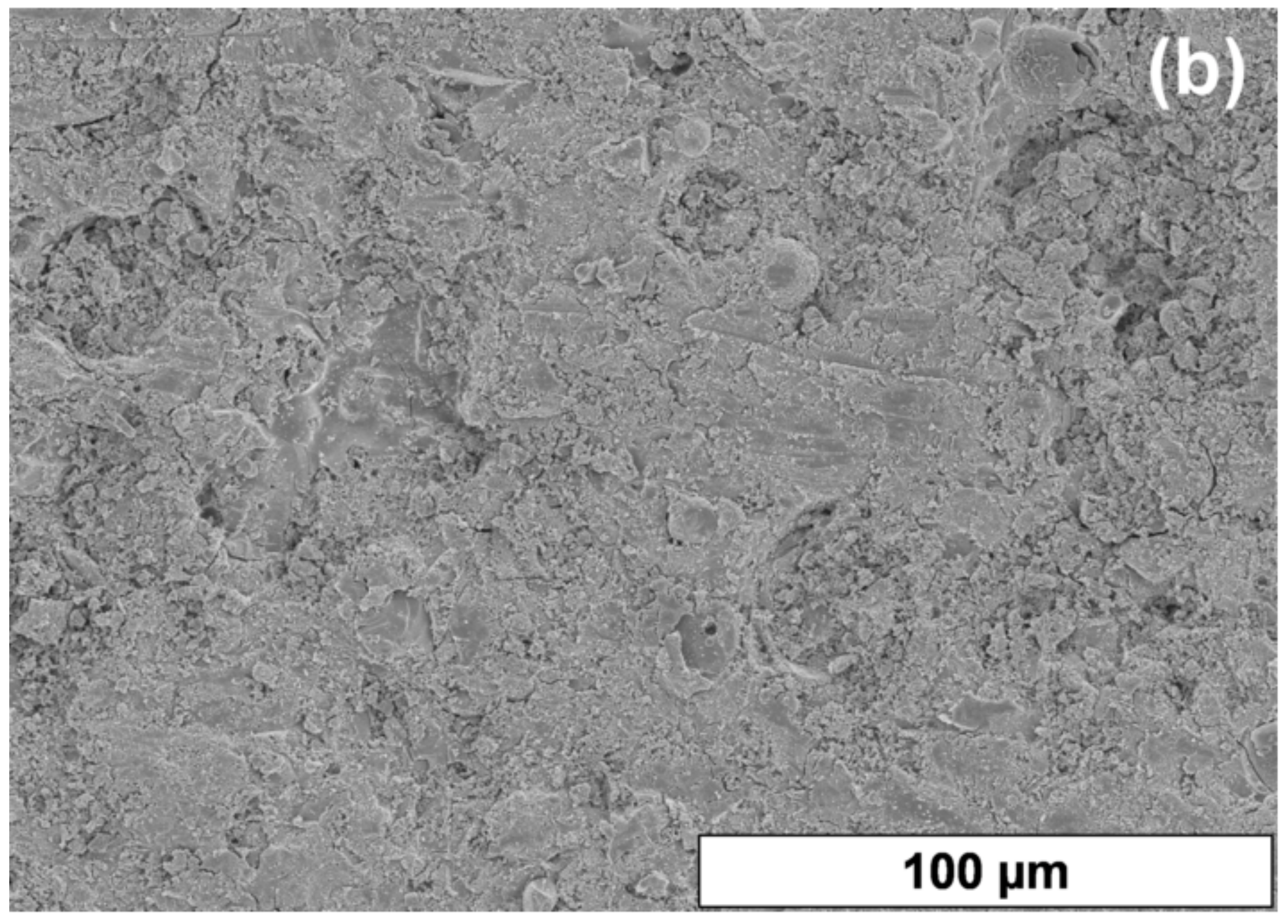

Figure 11b
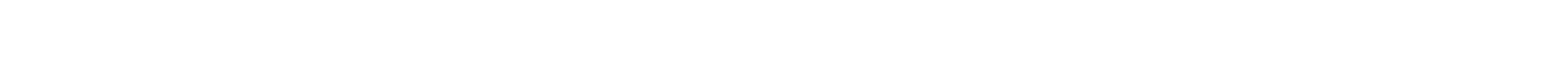

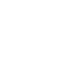

\author{
$100 \mu \mathrm{m}$
} $-2035$ .

$$
\text { . }
$$

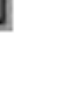

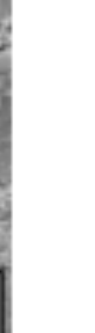




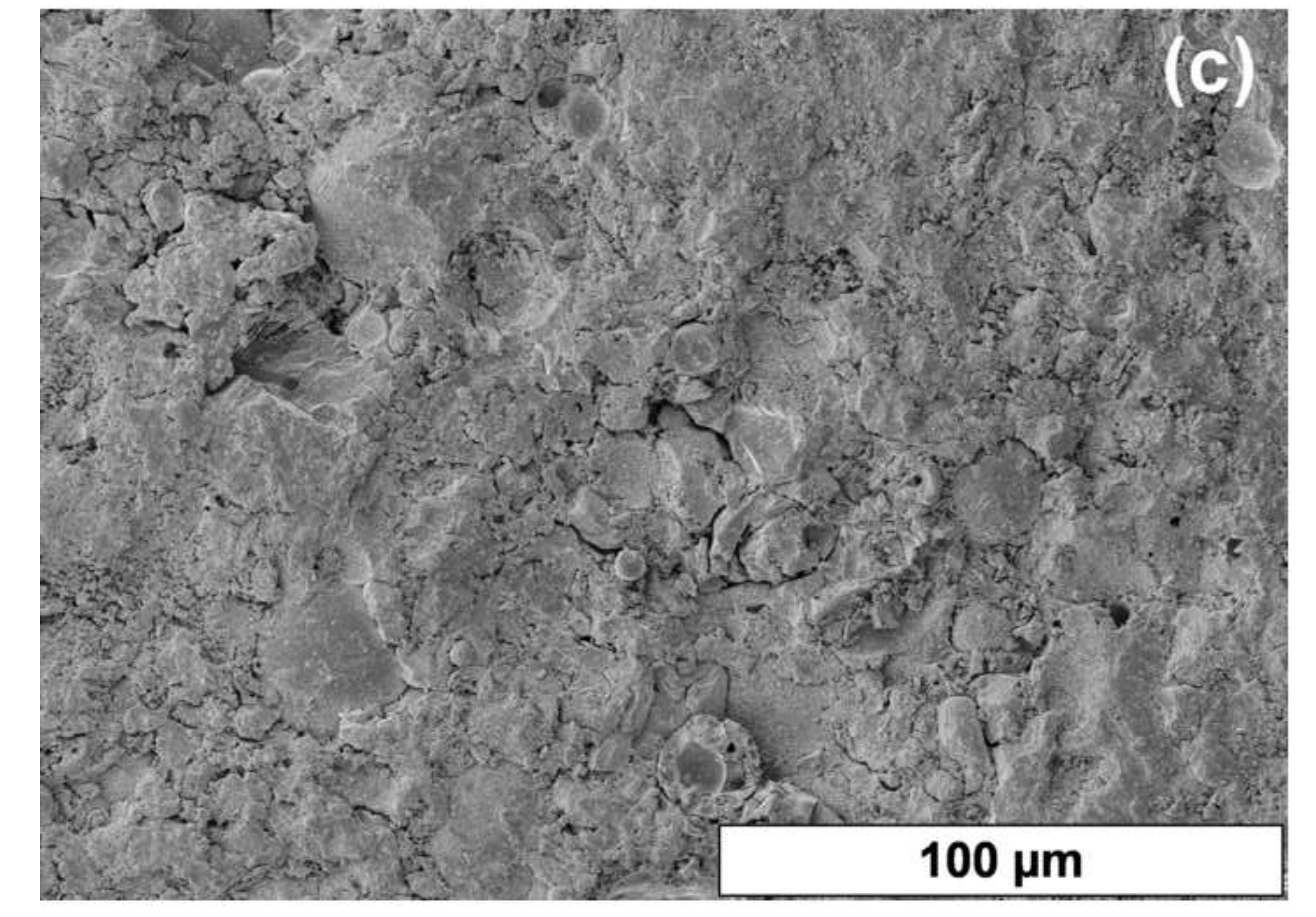

.

\footnotetext{
.
} 

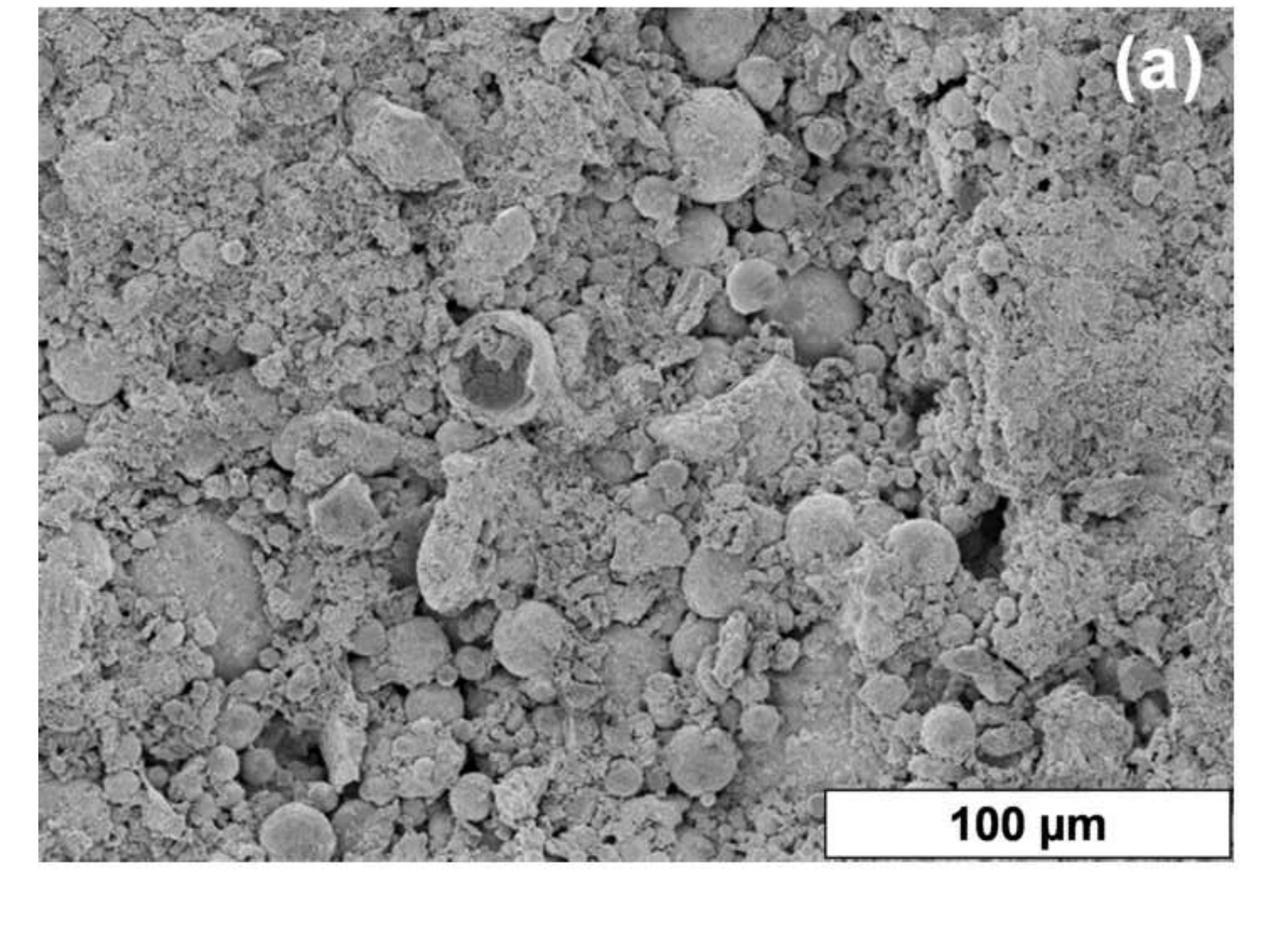

$$
\text { ( }
$$
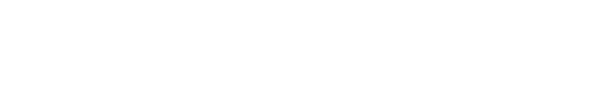

至

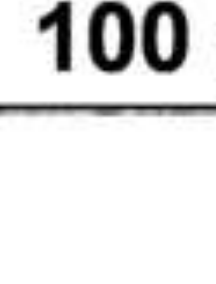
( .

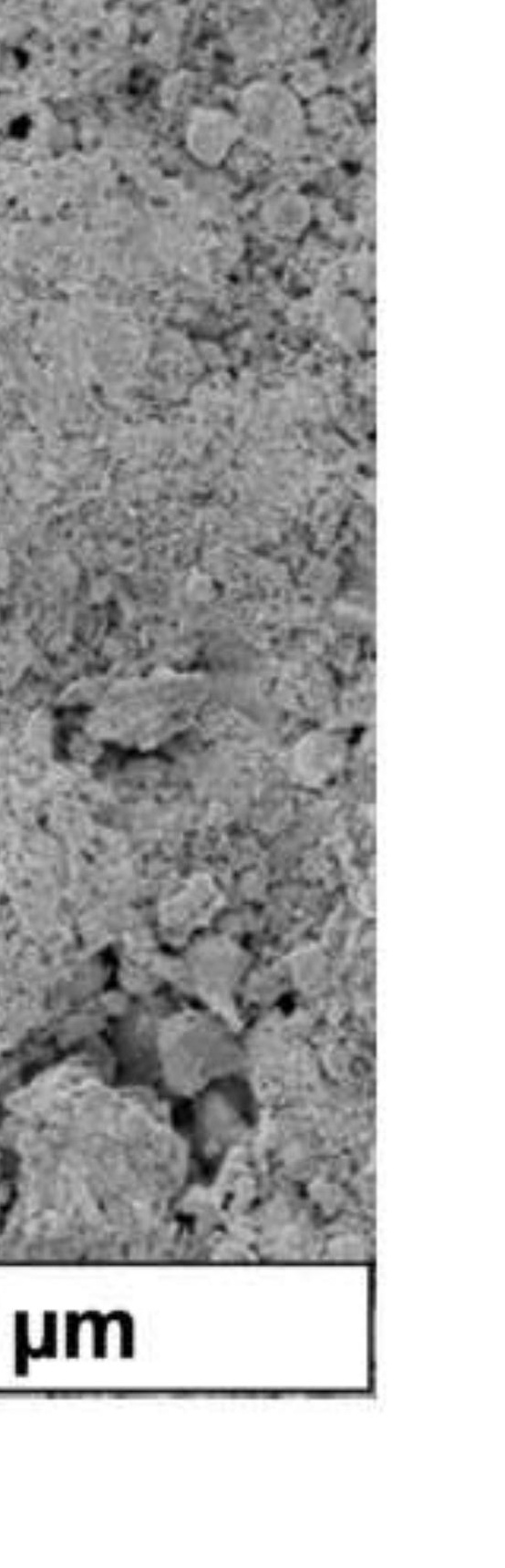

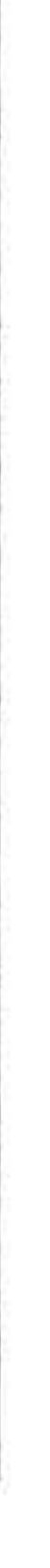
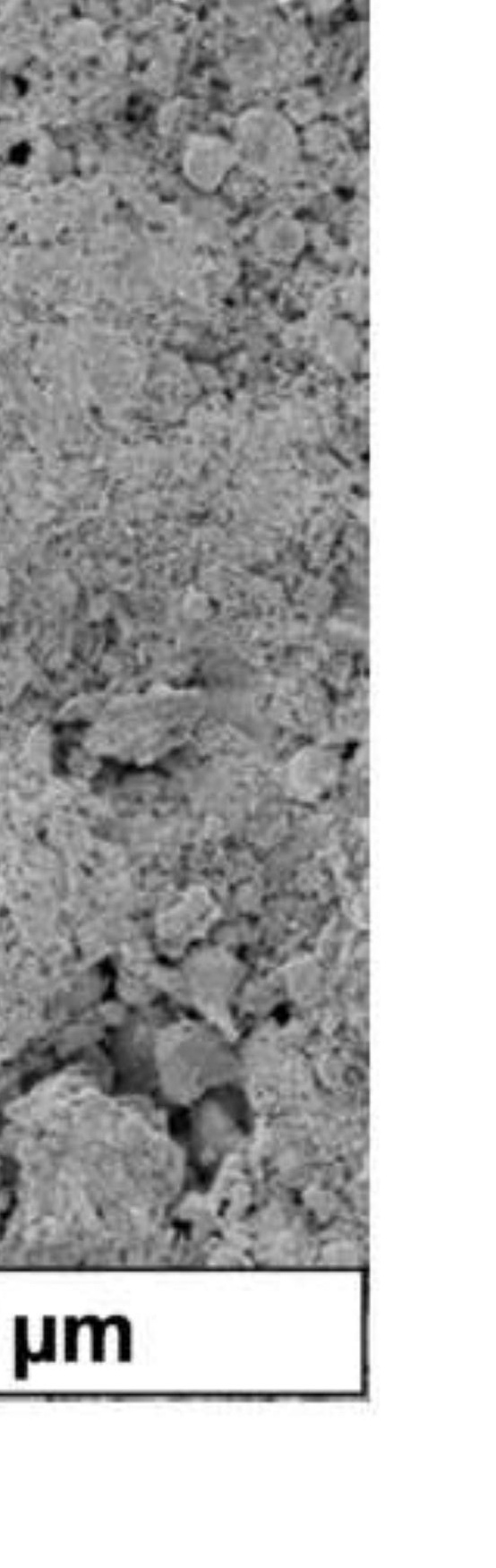


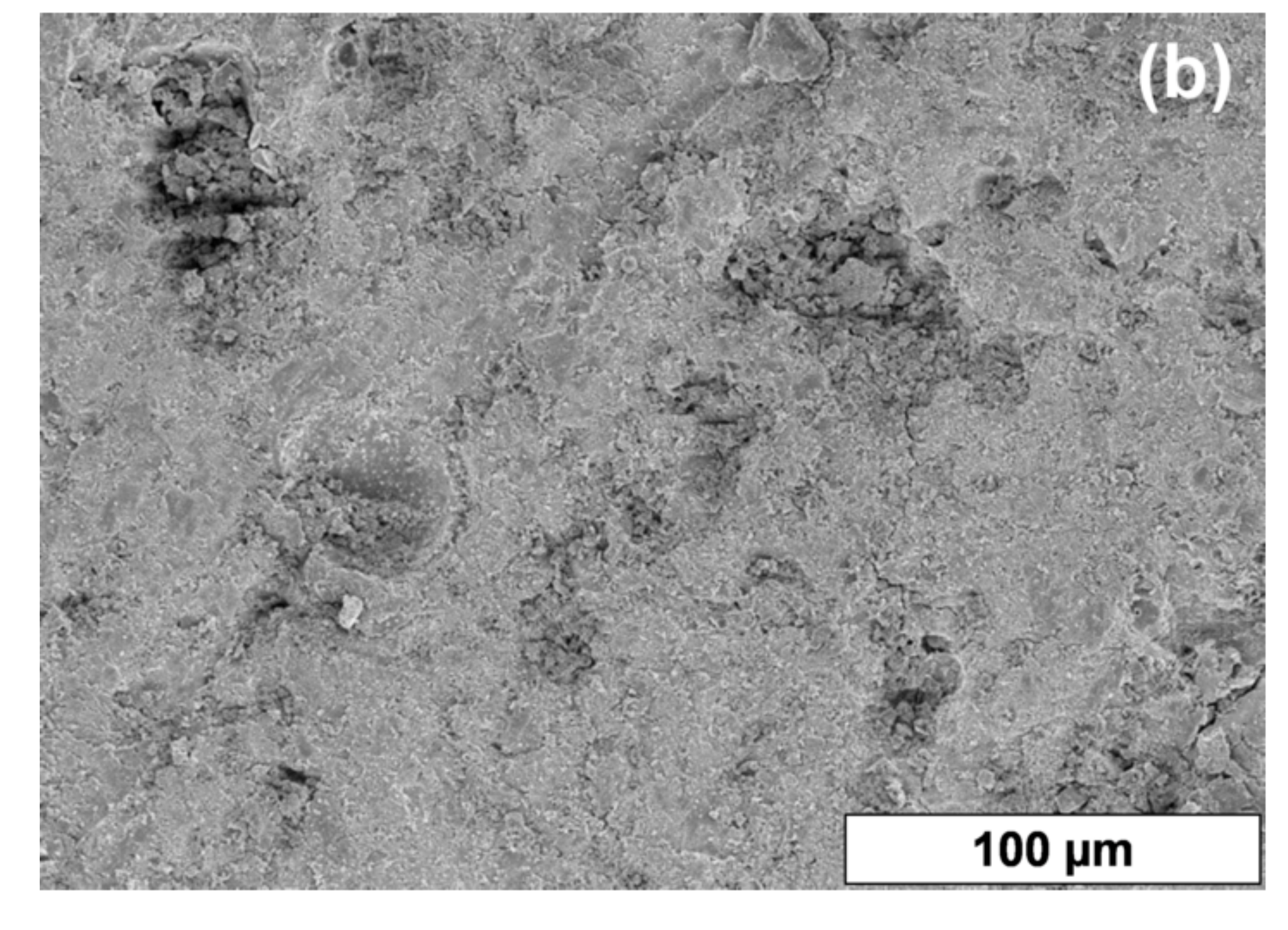

.
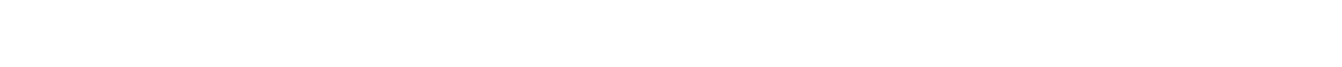
